\title{
Myalgic encephalomyelitis/chronic fatigue syndrome and encephalomyelitis disseminata/ multiple sclerosis show remarkable levels of similarity in phenomenology and neuroimmune characteristics
}

Gerwyn Morris ${ }^{1,2^{*}}$ and Michael Maes ${ }^{2,3}$

\begin{abstract}
Background: 'Encephalomyelitis disseminata' (multiple sclerosis) and myalgic encephalomyelitis/chronic fatigue syndrome (ME/CFS) are both classified as diseases of the central nervous system by the World Health Organization. This review aims to compare the phenomenological and neuroimmune characteristics of MS with those of ME/CFS.

Discussion: There are remarkable phenomenological and neuroimmune overlaps between both disorders. Patients with ME/CFS and MS both experience severe levels of disabling fatigue and a worsening of symptoms following exercise and resort to energy conservation strategies in an attempt to meet the energy demands of day-to-day living. Debilitating autonomic symptoms, diminished cardiac responses to exercise, orthostatic intolerance and postural hypotension are experienced by patients with both illnesses. Both disorders show a relapsing-remitting or progressive course, while infections and psychosocial stress play a large part in worsening of fatigue symptoms. Activated immunoinflammatory, oxidative and nitrosative (O+NS) pathways and autoimmunity occur in both illnesses. The consequences of O+NS damage to self-epitopes is evidenced by the almost bewildering and almost identical array of autoantibodies formed against damaged epitopes seen in both illnesses. Mitochondrial dysfunctions, including lowered levels of ATP, decreased phosphocreatine synthesis and impaired oxidative phosphorylation, are heavily involved in the pathophysiology of both MS and ME/CFS. The findings produced by neuroimaging techniques are quite similar in both illnesses and show decreased cerebral blood flow, atrophy, gray matter reduction, white matter hyperintensities, increased cerebral lactate and choline signaling and lowered acetyl-aspartate levels.
\end{abstract}

Summary: This review shows that there are neuroimmune similarities between MS and ME/CFS. This further substantiates the view that ME/CFS is a neuroimmune illness and that patients with MS are immunologically primed to develop symptoms of ME/CFS.

Keywords: Encephalomyelitis disseminata, Myalgic encephalomyelitis, Chronic fatigue syndrome, Inflammation, Autoimmunity, Oxidative and nitrosative stress, Mitochondria

\footnotetext{
*Correspondence: activatedmicroglia@gmail.com

${ }^{1}$ Tir Na Nog, Pembrey, Llanelli, UK

${ }^{2}$ Department of Psychiatry, Chulalongkorn University, Bangkok, Thailand

Full list of author information is available at the end of the article
} 


\section{Background}

'Encephalomyelitis disseminata'/multiple sclerosis (MS) and myalgic encephalomyelitis/chronic fatigue syndrome (ME/CFS) are both classified as diseases of the central nervous system by the World Health Organization (WHO). MS exhibits an almost bewildering radiological, clinical, and pathological heterogeneity. Evidence reveals that different processes, such as autoimmunity, inflammation and virus infection, may induce the pathology characteristic of the disease and suggests that MS is an illness involving the presence of different causative mechanisms. Distinct patterns of demyelination have been repeatedly documented. Two patterns bear a very close resemblance to autoimmune encephalomyelitis induced either by $\mathrm{T}$ cells alone or $\mathrm{T}$ and $\mathrm{B}$ cells in combination. The other patterns are highly indicative of virus infection or demyelination generated by exposure to environmental toxins rather overt autoimmune mechanisms. Pathological, biochemical and immunological data indicate that different pathways are generating the distinct pathology visible in different MS patients [1]. Research repeatedly demonstrates a proinflammatory milieu in MS patients as reflected by elevated levels of proinflammatory cytokines [2,3].

Patients with ME/CFS experience disabling levels of fatigue, as do people with MS, and they also have a wide range of neurological signs. The latter involve neurocognitive and autonomic symptoms, for example, postural hypotension and orthostatic intolerance $[4,5]$ and a wide range of abnormalities on brain scans indicating elevated levels of lactate, cerebral hypoperfusion, and glucose hypometabolism [5]. Evidence shows that different trigger factors, such as infections and (auto)immune disorders, may be associated with the onset of ME/CFS [6]. ME/CFS patients display numerous immune abnormalities indicating an activated but dysregulated immune system, including chronically elevated levels of cytokines, signs of immune activation, loss of $\mathrm{T}$ cell homeostasis, decreased natural killer cell activity and autoimmune responses [6].

This review aims to compare the diseases of MS and ME/CFS on several different dimensions. These dimensions will include phenomenological similarities, including symptoms and course, elevated oxidative and nitrosative stress $(\mathrm{O}+\mathrm{NS})$, the existence of autoimmunity, cell mediated immunity and cytokine abnormalities and abnormalities in T cell activation and homeostasis, and a comparison of brain imaging findings. It is worth noting at the onset, however, that although CFS is recognized as an alternative term to myalgic encephalomyelitis there are many instances in the literature where the term is used as a synonym for fatigue of a psychiatric or idiopathic origin and patients are selected who only experience fatigue [7]. In this review we only consider data from studies where patients are recruited using CDC criteria and eschew studies where patients are selected because they meet arbitrary criteria produced by unvalidated or invalidated symptom questionnaires or generic fatigue scales. Trying to synthesize results where selection criteria are major confounding variable is virtually impossible, and in any event can lead to false conclusions [8].

\section{Discussion}

\section{Phenomenological similarities between MS and ME/CFS}

Many patients with MS have symptoms that are characteristic for ME/CFS. We will first discuss the typical symptoms of ME/CFS and then show that many patients with MS also have ME/CFS symptoms in conjunction with typical neurological deficits. People with ME/CFS can have a wide range of symptoms [9]. Typical symptoms include chronic fatigue, hyperalgesia, migraine-type headaches, unrefreshing sleep or even sleep/wake cycle reversal. Patients also present with symptoms consistent with a chronic influenza-like syndrome. These symptoms include unrelenting severe disabling fatigue in the physical and mental domains combined with incapacitating levels of muscle fatigability. Problems with memory retrieval and formation are also frequently observed. Problems with word retrieval mean that patients are frequently unable to finish sentences. These symptoms are all made worse by increases in cognitive and or physical activity. An inability to tolerate even trivial increases in physical or mental activity above individual norms is the hallmark symptom of ME/CFS [5]. This intolerance manifests itself in disease exacerbation, which may be short lived or prolonged $[10,11]$. ME/CFS patients display abnormalities in parameters appertaining to sympathetic and parasympathetic nervous system activity $[12,13]$. Orthostatic intolerance, and neurally mediated hypotension are commonly reported cardiovascular symptoms $[4,14]$. Postural orthostatic tachycardia syndrome (POTS) is another common finding. Exaggerated postural tachycardia and enhanced sympathetic activity have been reported [12,15]. Autonomic symptoms also include an intolerance of wide temperature fluctuations and grossly impaired thermostatic stability. A diminished cardiac response to exercise has also been demonstrated [16]. Resting sympathetic overactivity coupled with reduced vagal modulation appears to be a reproducible finding in ME/CFS [17]. De Becker et al. [18] reported a sympathetic drive increased heart rate (HR) on tilt compared to controls. Another study demonstrated impaired HR responses indicating the existence of attenuated cardiac sympathetic responsiveness. These lower HR responses could not be reconciled with an explanation based on patient deconditioning or prolonged inactivity [19]. Those authors reported that hemodynamic responses in patients with ME/CFS were significantly impaired during exercise compared to healthy controls. A number of other workers have reported autonomic dysregulation in people with ME/CFS [20-27]. Patients with ME/CFS 
typically use energy conservation strategies or pacing as a method of minimizing the effects of their fatigue on daily living [28].

Around 53\% to $92 \%$ of MS patients experience disabling levels of fatigue [29]. Patients with MS frequently report that their fatigue is unremitting and relentless [30-32], and causes daytime sleepiness [33] and an irresistible urge to rest [32]. Clinically, fatigue presents as exhaustion, loss of energy, daytime somnolence, or exacerbation of symptoms. Activity usually acts to increase fatigue levels in MS [34]. Thus, the experience of permanent exhaustion is magnified by exacerbations leading to complete absence of energy after physical or cognitive activity [35,36]. Rapid exhaustion and markedly reduced exercise tolerance is a source of profound disability in patients with MS [36]. People with MS not only report a lack of energy, but also a profound intolerance of even minor physical activities $[31,33,37]$. MS patients often have concentration difficulties or an inability to complete mental tasks [30,33,37]. Reports of malaise are also commonplace [32,37].

The most frequent symptoms of autonomic dysfunction in MS patients are impotence, gastrointestinal dysfunction, sleep disturbances, disordered micturition and orthostatic intolerance [38,39]. Patients may develop POTS as a result of their underlying autonomic dysfunction [40]. A number of different groups have reported orthostatic dysregulation, neurocardiogenic syncope and cardiac dysrhythmias [41-44].

People with MS also use pacing strategies to minimize the effects of their fatigue on daily living. Such strategies include planning daily routines, ensuring that periods of higher activity take place in the mornings and budgeting time for rest or even sleep between such periods of increased activity [37]. A number of studies have empirically examined the effectiveness of pacing by enrolling patients in a course where they were given instructions in various pacing techniques [45-47]. These courses resulted in significant reductions in fatigue.

In summary (see Table 1), patients with ME/CFS and MS both experience severe levels of disabling fatigue and a worsening of symptoms following exercise and resort to energy conservation strategies in an attempt to meet the energy demands of day-to-day living. Debilitating autonomic symptoms are experienced by people with both illnesses. Diminished cardiac responses to exercise are a common finding as are reports of orthostatic intolerance and postural hypotension. It appears, however, that ME/CFS patients may be more sensitive to physical or cognitive activities than patients with MS.

\section{Similarities in the course and other disease characteristics of MS and ME/CFS}

There are four MS types, outlined below. (1) Patients with relapsing-remitting type MS endure relapses or
Table 1 Phenomenological similarities between encephalomyelitis disseminata/multiple sclerosis (MS) and myalgic encephalomyelitis/chronic fatigue syndrome (ME/CFS)

\begin{tabular}{lcc}
\hline Phenomenology & MS & ME/CFS \\
\hline Disabling fatigue & $\checkmark$ & $\checkmark$ \\
Severe exercise intolerance & $\checkmark$ & $\checkmark$ \\
Mental fatigue & $\checkmark$ & $\checkmark$ \\
'Pacing' as an energy conservation strategy & $\checkmark$ & $\checkmark$ \\
Worsening of symptoms following exercise & $\checkmark$ & $\checkmark$ \\
Orthostatic intolerance & $\checkmark$ & $\checkmark$ \\
Gastrointestinal dysfunction & $\checkmark$ & $\checkmark$ \\
Cardiac dysrhythmias & $\checkmark$ & $\checkmark$ \\
Postural hypotension & $\checkmark$ & $\checkmark$ \\
Diminished cardiac response to exercise & $\checkmark$ & $\checkmark$ \\
Relapsing-remitting nature & $\checkmark$ & $\checkmark$ \\
Chronic course & $\checkmark$ & $\checkmark$ \\
Disease exacerbated by infections & $\checkmark$ & $\checkmark$ \\
Disease exacerbated by psychological stress & $\checkmark$ \\
Disease worsened or precipitated by infections & $\checkmark$ & $\checkmark$ \\
\hline
\end{tabular}

episodes of acute impairment of neurologic function. Relapses may be replaced by times of partial or complete remissions without further exacerbations. This is easily the most common presentation of MS and people with relapsing-remitting MS make up about $85 \%$ of the MS population. (2) Patients with primary-progressive type MS endure a continuous deterioration of their disease typically, but not exclusively, without a pattern of relative relapse or remission. This phenotype is relatively rare comprising about $10 \%$ of the MS population. (3) Patients with secondary-progressive type MS endure an initial pattern of relapsing-remitting disease followed by a progressive deterioration of disease activity amidst a pattern of minor relapses and remissions. Around half of those with the relapsing-remitting course of disease will go on to develop secondary-progressive MS in the absence of treatment. (4) Patients with progressive-relapsing type MS experience a progressive worsening of symptoms from onset coupled with acute exacerbations with or without recovery. There is no period of remission in this form of MS. The frequency of this phenotype is approximately $5 \%$ of the total MS population.

In addition, ME/CFS is a chronic, relapsing-remitting disease involving the waxing and waning of symptoms [48-51]. The majority of studies examining longitudinal changes in disease activity using internationally agreed diagnostic criteria report a relapsing-remitting or progressive pattern of disease in the patients monitored [52-55]. Recovery from ME/CFS is extremely rare [53-55]. The average figure reported in studies using 1988 or 1994 Centers for Disease Control and Prevention recruitment 
criteria is some $4 \%[53,55,56]$. Peterson et al. [57] reported a relative remission in some $40 \%$ of patients monitored over 12 months while $20 \%$ of patients demonstrated progressive worsening of their disease and 40\% remained stable. Unfortunately, none recovered. Saltzstein et al. [58] reported very similar statistics.

Different trigger factors such as infections and other environmental factors play a role in the onset of MS and ME/CFS. Infections have been implicated in relapse of MS. Activation of immune pathways, mostly via cytokines, is believed to be responsible for the occurrence of severe relapses during or following infection [59]. Stress also increases the frequency of relapses or a general worsening of symptoms [60]. Stress leads to elevated cytokines and increases in general proinflammatory states, which may well create the environment fostering increased disease activity $[61,62]$.

The vast majority of ME/CFS patients endure multiple persistent bacterial and viral infections [63-70]. The existence of these infections correlates positively with the total number of symptoms and the severity of those symptoms including the neurological symptoms [66]. Concurrent infections appear to worsen symptoms globally [71]. Stress is also related to worsening symptoms of ME/CFS [72,73].

The incidence and prevalence of MS demonstrates considerable geographic variability [74,75]. High frequency areas (prevalence of 60 per 100,000 or more) include Europe, the area encompassing the northern USA and Southern Canada, the antipodes including all of New Zealand, the south eastern part of Australia. In the US, the prevalence is 100 per 100,000 . At a rate of $300 /$ 100,000 , the residents of the Orkney Islands in the UK have a disproportionately heavy burden.

Estimating the prevalence of ME/CFS is a difficult exercise however. Although the disease was first reported in 1934, the introduction of new descriptive terminology in 1988 following an outbreak of ME in the USA led many physicians to equate the disease with idiopathic chronic fatigue. The presence of chronic fatigue in a population is common, ranging from just under 3,000 to just over 6,000 cases per 100,000 [76]. While disabling fatigue is certainly present in most people it is just one of an array of disabling neurological and neuroendocrine symptoms experienced by patients with ME/CFS. With that proviso in mind, the figures would indicate that some $0.2 \%$ of the people in the USA have ME/CFS [76-80], which is twice the prevalence of MS. As in many autoimmune disorders, ME/CFS and MS are more prevalent in women than in men $[9,81]$.

Table 1 shows the phenomenological similarities between both disorders. Both MS and ME/CFS show a chronic and/or relapsing-remitting course, while infections and stress appear to play a large part in worsening of symptoms in both illnesses. Immune activation following infection is believed to trigger relapses in MS and ME/CFS. Patients with ME/CFS have more concomitant infections and the number of different infections correlates with the severity of symptoms. Stress is related to worsening of symptoms of fatigue in both MS and ME/ CFS.

\section{Oxidative and nitrosative stress}

Accumulating data demonstrates that $\mathrm{O}+\mathrm{NS}$ plays a significant role in the pathophysiology of MS $[82,83]$. Studies have revealed the existence of lipid peroxidation in MS as evidenced by elevated levels of the alkanes pentane and ethane, hydrocarbons produced by peroxidation of unsaturated fatty acids [84]. O+NS likely make a major contribution to the pathophysiology of lesions in patients with MS [85]. Peroxinitrite for example is capable of modifying lipid, protein, DNA and mitochondrial structures and functions via the production of oxidizing and nitrating free radicals. Evidence supporting the presence of $\mathrm{O}+\mathrm{NS}$ in demyelinating and inflammatory lesions includes the existence of nitrotyrosine together with lipid and protein peroxides [86,87]. Increased nitric oxide (NO) and inducible nitric oxide synthase (iNOS) production have been detected in peripheral blood mononuclear cells caused by raised levels of oxidative stress $[87,88]$. Isoprostanes, isomers of prostaglandins, are generated by peroxidation of fatty acids and can be detected in the urine as well as in the plasma from people with MS [89-91]. Elevated levels of isoprostane 8epi-prostaglandin are found in the cerebrospinal fluid (CSF) of patients with MS [92].

Many studies using peripheral blood measures have shown increased $\mathrm{O}+\mathrm{NS}$ in patients with ME/CFS, including increased levels of malondialdehyde (MDA), isoprostane, 8-OH-deoxyguanosine, 2,3 diphosphoglyceric acid, thiobutyric acid, and protein carbonyls [93-101]. The production of iNOS is significantly increased in ME/CFS patients as compared with normal controls [102]. As we will discuss below, there is also evidence that there is a chronic hyperproduction of NO [93]. Raised oxidative stress levels also occur in response to exercise in ME/CFS [103] potentially explaining one of the mechanisms underlying post-exertional malaise. In ME/CFS patients, exercise induces striking changes in the excitability of muscle membranes [104]. Skeletal muscle oxidative imbalance contributes to increased muscle fatigability [105]. Several authors have reported that $\mathrm{O}+\mathrm{NS}$ measures demonstrate a significant and positive correlation with symptom severity [93-96,99,101,106,107].

Both MS and ME/CFS are accompanied by significantly depressed levels of crucial antioxidants and antioxidant enzymes. Syburra and Passi [108] reported low levels of vitamin E, ubiquinone (coenzyme Q10) and 
glutathione (GSH) peroxidase in MS. de Bustos et al. [109], however, did not find significant differences in serum levels of coenzyme Q10 between patients with MS and controls. There are reports on lowered levels of glutathione in the brains of MS patients [110]. Lowered zinc levels have been observed in MS [111].

Lowered levels of zinc, coenzyme Q10 and glutathione have been reported in ME/CFS [95,107,112]. A recent proton magnetic resonance spectroscopy study reported decreased cortical glutathione levels in the brain in ME/ CFS that inversely correlated with lactate levels [107]. A study examining blood vitamin E levels showed that amelioration of oxidative stress occurs when ME/CFS patients enter remission [100].

Table 2 shows the similarities in $\mathrm{O}+\mathrm{NS}$ pathways between both disorders. Markers of elevated $\mathrm{O}+\mathrm{NS}$ are found in both illnesses. Moreover, the abnormalities reported are virtually identical in both illnesses and include elevated levels of peroxinitrite, NO and iNOS. Evidence of nitrosatively modified amino acids and proteins and oxidatively modified lipids are found in both illnesses. Reduced levels of antioxidants, including vitamin $\mathrm{E}$, zinc and glutathione are also found in both diseases. While coenzyme Q10 is clearly related to fatigue in ME/ CFS, the findings in MS are less evident.

\section{Cytokine levels in MS and ME/CFS}

Studies have repeatedly reported elevated levels of the proinflammatory cytokines, IL-1 $\beta$ [113-115], TNF $\alpha$ $[115,116]$ and IL-6 $[117,118]$ in the CSF and plasma of people with MS. Moreover, the cytokine pattern observed in the CSF of patients with relapsing-remitting MS varies depending on the stage of the disease [119].

\begin{tabular}{|c|c|c|}
\hline Oxidative and nitrosative stress $(\mathrm{O}+\mathrm{NS})$ & ED/MS & $\mathrm{ME} / \mathrm{CFS}$ \\
\hline Lipid peroxidation & $\checkmark$ & $\checkmark$ \\
\hline Increased malondialdehyde & $?$ & $\checkmark$ \\
\hline Elevated peroxynitrite & $\checkmark$ & $\checkmark$ \\
\hline Nitrated amino acids & $\checkmark$ & $\checkmark$ \\
\hline Elevated nitric oxide (NO) & $\checkmark$ & $\checkmark$ \\
\hline Elevated inducible NO synthase (iNOS) & $\checkmark$ & $\checkmark$ \\
\hline Raised isoprostane levels & $\checkmark$ & $\checkmark$ \\
\hline Low vitamin $\mathrm{E}$ & $\checkmark$ & $\checkmark$ \\
\hline Reduced levels of glutathione & $\checkmark$ & $\checkmark$ \\
\hline Low zinc levels & $\checkmark$ & $\checkmark$ \\
\hline Low coenzyme Q10 concentrations & $?$ & $\checkmark$ \\
\hline O+NS implicated in pathology & $\checkmark$ & $\checkmark$ \\
\hline
\end{tabular}

Th1-like cytokines, such as IL-2, and interferon (IFN), and interleukin (IL)-12, are increased during active disease. T helper (Th)2 cytokines, such as the anti-inflammatory IL10 , transforming growth factor (TGF)- $\beta$ and IL-4, are elevated during relative remission [120-123]. Th1 and Th2 cytokines are present in the CSF and lesions [124,125] during relapse and remission. The high concentrations of tumor necrosis factor (TNF) $\alpha$ and IL-10 (both in serum and CSF), which accompany an MS attack, suggest a concomitant expression of Th1 and Th2 cytokines and not to the sequential expression of Th1 cytokines followed by Th2 cytokines [126].

A number of studies have found increased levels of the major proinflammatory cytokines TNF $\alpha$ and IL-1 $\beta$ in ME/CFS (for a review see Maes et al. [127]). Recent evidence has challenged the view that patients with ME/ CFS display an activated Th2 dominated immune system $[5,128]$. Proinflammatory and anti-inflammatory cytokines are known to coexist also in ME/CFS, although in many patients proinflammatory cytokines are dominant $[127,129,130]$. Studies examining the Th cytokine profiles in people with ME/CFS also show a large number of different findings almost certainly for methodological inconsistencies, including patient selection [5]. Rose et al. [131] reported that there was a significant upregulation of cyclo-oxygenase 2 (COX2), usually accompanied by increased iNOS, in MS lesions and opined that COX2 promoted excitotoxic death and damage of oligodendrocytes by coupling with iNOS. The involvement of COX2 in oligodendrocyte death was confirmed by Carslon et al. [132] using histopathological techniques. Upregulation of nuclear factor (NFKB in lesion-based macrophages amplifies the inflammatory reaction by stimulating the production of adhesion molecules and proinflammatory cytokines [133]. Activated NFKB is found at high levels in microglia of active lesions [134]. These authors proposed that high $\mathrm{NF \kappa B}$ levels explains the relative rarity of oligodendrocyte death in MS. Generally it seems that upregulation of $N F \kappa B$ in neurons is protective but activation of $\mathrm{NFKB}$ in microglia stimulates neuronal degeneration [135,136]. Maes et al. [102] reported significantly elevated levels of COX2 and $\mathrm{NF} \kappa \mathrm{B}$ in patients with ME/CFS compared to healthy controls. Moreover, the severity of the illness correlated significantly and positively with the elevation in concentrations COX2 and NFkB.

Table 3 displays the similarities in immunoinflammatory pathways between MS and ME/CFS. Overall, proinflammatory cytokines are elevated in MS and ME/CFS but the results of investigative trials depend on methodology and can vary according to the state of the disease. Th1 and Th2 cytokines coexist in both illnesses. COX2 and $\mathrm{NFKB}$ are upregulated in both disorders and may play a role in the pathophysiology of both MS and ME/CFS. 


\begin{tabular}{|c|c|c|}
\hline Immunoinflammatory pathways & ED/MS & ME/CFS \\
\hline $\begin{array}{l}\text { Raised levels of proinflammatory cytokines, } \\
\text { for example, interleukin (IL) } 1 \text { and tumor } \\
\text { necrosis factor-a }\end{array}$ & $\checkmark$ & $\checkmark$ \\
\hline Increased nuclear factor $\mathrm{KB}$ & $\checkmark$ & $\checkmark$ \\
\hline Increased cyclo-oxygenase 2 & $\checkmark$ & $\checkmark$ \\
\hline Raised IL-2 & $\checkmark$ & $\checkmark$ \\
\hline Raised IL-10 & $\checkmark$ & $\checkmark$ \\
\hline Raised transforming growth factor $\beta$ & $\checkmark$ & $\checkmark$ \\
\hline Coexistence of a T helper (Th) 1 and Th2 response & $\checkmark$ & $\checkmark$ \\
\hline Elevated osteopontin levels & $\checkmark$ & $\checkmark$ \\
\hline Temporal variation in cytokine profile & $\checkmark$ & $\checkmark$ \\
\hline Elevated neopterin & $\checkmark$ & $\checkmark$ \\
\hline T regulatory (Treg) dysfunction & $\checkmark$ & $\checkmark$ \\
\hline Forkhead box P3 (FOXP3) dysfunction & $\checkmark$ & $\checkmark$ \\
\hline Clonal exhaustion of T cells & $\checkmark$ & $\checkmark$ \\
\hline Elevated CD26 & $\checkmark$ & $\checkmark$ \\
\hline CD69 expression & $\uparrow$ & $\downarrow$ \\
\hline Low natural killer cell activity & $\checkmark$ & $\checkmark$ \\
\hline Chronic activation of immunoinflammatory pathways & $\checkmark$ & $\checkmark$ \\
\hline
\end{tabular}

Cell mediated immunity in MS and ME/CFS

Neopterin

Levels of neopterin have been reported as being higher in CSF of MS patients during exacerbations in comparison with remissions [136]. Increased urinary neopterin to creatinine ratio is an accurate surrogate marker of cell-mediated immune activation in MS [137]. Relapses and disease activity are related to increased neopterin levels [138-140]. Many studies have detected high levels of serum neopterin in ME/CFS [127,141-144].

\section{Regulatory $T$ cells}

$\mathrm{T}$ cells are anergized in patients with MS in remission [145] indicating functioning regulatory $\mathrm{T}$ (Treg) cells. The situation in active disease is quite different however. Programmed death 1 (PD-1)-regulatory T cells are elevated in the peripheral blood of relapsing-remitting MS with active disease [146] and these Treg cells appear to be clonally exhausted $[146,147]$ and only a small fraction express PD-1 receptors which are needed for their suppressive function [146]. An absence of PD-1 expression on forkhead box P3 (FOXP3) + CD4+ T cells greatly reduces their ability to suppress the activity of effector $\mathrm{T}$ cells, which is essential if self-tolerance is to be maintained and autoimmunity to be prevented [148]. A number of studies report impaired function of Tregs in active disease $[149,150]$. Tregs can react to inflammation by increasing numbers in active disease in an attempt to restore homeostasis [151]. PD-1 also has a key role in the modulation of $\mathrm{T}$ cell function during a prolonged viral infection. The functional impairment of $\mathrm{T}$ cells that occurs during chronic viral infections is considered to be due to $\mathrm{T}$ cell exhaustion promoted by activation of the PD-1 pathway and elevation of Tregs as the infection progresses $[148,152,153]$. Defective Treg function in people with MS is shown by the existence of Th17 lymphocytes in the peripheral circulation and the CNS [154-156]. Patients with relapsing-remitting MS display a Th1/Th17 phenotype in active disease $[157,158]$. Reduction in Treg function leads to a Th1/ Th17 phenotype resulting from activation of naive $\mathrm{T}$ cells $[159,160]$.

Compared to healthy controls, ME/CFS patients display statistically significant increases in CD4(+)CD25(+) Treg cells and FOXP3 expression [161]. Interestingly, chronically elevated IL-2 expression leads to the exhaustion of FOXP3 expression on CD25 + CD4+ Treg cells over time [159]. IL-2 is found chronically activated in MS [162-165] and ME/CFS [166,167]. This also indicates that a chronically activated immune system may exist in both diseases caused by a failure of the FOXP3/IL-2 feedback mechanism [168]. The pattern of raised IL-2 levels and chronic immune activation with disrupted homeostasis $[169,170]$ coupled with raised levels of Treg cells seen in patients with ME/CFS strongly suggests Treg cell exhaustion as a feature of this disease as well. Strong evidence of $\mathrm{T}$ cell exhaustion has been reported in ME/ CFS patients by many different researchers [171-175].

\section{CD26+ and CD69+ $T$ cells}

Further evidence of an activated or dysregulated immune system is provided by a consideration of the data relating to the CD26 and CD69 T cell receptors in both MS and ME/CFS. CD26 is a T cell activation antigen with dipeptidyl peptidase 4 (DPPIV) activity [176]. CD26 as a surrogate marker of $\mathrm{T}$ cell activation correlates well with the activity of a number of autoimmune diseases $[177,178]$. CD26 is a marker of T cell activation and autoimmunity $[179,180]$ and a key modulator of immune responsiveness [181]. CD26 expression is associated with Th-17 cells and IL-17 production is related to the CD26+ CD4+ T cell subset [182]. Memory CD4+ T cells with high expression of CD26+ correlate with clinical severity of MS $[183,184]$. The likelihood of a relapse is approximately three times higher in MS patients with high CD26 levels [185]. Importantly, elevated CD26 + CD4+ T cell numbers have been reported in people with ME/CFS compared to controls [186].

Another inhibitory regulator of Th17 cell differentiation is CD69, an early activation marker that promotes activation of the signal transducer and activator of transcription 
5 (STAT5) pathway [187]. Patients with MS show an increased CD69 expression on T Lymphocytes [188]. The less pronounced IFN-induced effects on CD69 expression in MS versus controls is evidence of a defect in immunoregulation [189]. In ME/CFS, significantly lower CD69 expression on mitogen stimulated $\mathrm{T}$ cells has been detected [190]. This decreased expression of CD69 upon stimulation was strongly associated with inflammatory markers and indicates a defect in the initial activation of T lymphocytes and natural killer (NK) cells [112,190].

\section{NK cells in MS and ME/CFS}

Both MS and ME/CFS are accompanied by reduced and impaired activity of NK cells (NKCs). NKCs have a key role in immunoregulation. Crosstalk between NKCs and dendritic cells acts as a rheostat for the immune system and hence NKCs play a pivotal role in maintaining immune homeostasis [191] and in the suppression of T cell responses. In addition, NK CD56 bright cells have also a major role in combating autoimmunity. Benczur et al. [192] reported that NKC function was reduced in people with active disease compared with those in remission. Enhancement of NKC CD56 function leads to an amelioration of symptoms in MS [193]. Longitudinal disease activity, determined both clinically and by serial magnetic resonance imaging (MRI), correlates with natural killer cell activity (NKCA) and phenotype. Mean NKCA is significantly reduced in patients with MS as compared to normal controls. In relapsing-remitting $\mathrm{MS}$, there is a significant association between lowered NKCA and the onset of new lesions on MRI [194]. In patients with MS, CD56 bright NKCs mediate immunoregulation [193]. Takahashi et al. [195] reported that a subset of NKCs was responsible for the maintenance of remission in relapsing-remitting MS and the development of relapses $[192,195]$ and expansion corresponds with remission [196]. In ME/CFS, reduced and impaired NKC functioning has been a consistent finding reported by many authors $[173,197,198]$.

It is tempting to speculate that gender-related differences in immune responsiveness may be associated with the higher prevalence of ME/CFS and MS in women as compared to men. The immunological processes occurring in the effector phase and induction of $\mathrm{T}$ cell priming are much stronger in female mice [81].

\section{Summary}

Table 3 shows that markers of immune activation are comparable in both illnesses. Elevated neopterin levels and elevated expression of the CD26 antigen on T cells demonstrate chronic immune activation while chronically elevated IL-2 levels indicate dysfunctional T cell activation and disordered homeostasis. Defective functionality of Treg cells is evidenced in both illnesses and clonal exhaustion of $\mathrm{T}$ cells is found in patients with MS and ME/CFS. There are, however, also differences between both disorders. Thus, clonal exhaustion may be limited to Treg cells in the active stage of MS, while the T cell exhaustion in patients with ME/CFS may be more global. While MS is characterized by increased in vivo expression of CD69, a decreased ex vivo CD69 expression is found in $\mathrm{ME} / \mathrm{CFS}$. Both MS and ME/CFS are accompanied by reduced NKCA.

\section{$B$ cells and autoimmunity in MS and ME/CFS $B$ cells}

Increased numbers of $\mathrm{B}$ cells are observed in $\mathrm{ME}$ and $\mathrm{ME} / \mathrm{CFS}$. CD80+ B cells numbers are increased in relapse phases of MS, relative to the values found in patients in remission or healthy controls [199]. Increases in the number of mature CD19 B cells have been reported in ME/ CFS patients [200-202]. Klimas et al. [173] reported elevated numbers of CD20+ and CD21+ B cells in ME/CFS. Activated B cells possess a high capacity to generate inflammatory and regulatory cytokines and have a regulatory function in autoimmune diseases [203].

\section{Autoimmunity}

MS is widely considered to be at least in part an autoimmune disorder. Autoimmune reactions are also highly prevalent in ME/CFS. The presence of anti-nuclear antibodies and antibodies directed against cardiolipin and other phospholipids has been reported in some patients with MS [204-206]. Anti-neuronal antibodies, anti-muscle antibodies, anti-ganglioside antibodies [207-209] and antiserotonin antibodies [210] are also active in MS.

Many individuals with ME/CFS show several indicators of autoimmune responses. Anti-cardiolipin antibodies have been reported in people with ME/CFS [211,212]. Konstantinov et al. [213] reported the presence of autoantibodies to nuclear envelope antigens. Anti-neuronal antibody levels are elevated in ME/CFS patients with neurologic abnormalities [214]. Other indicators include elevated antibody titers towards phospholipids, gangliosides and serotonin; anti-lamine SS DNA as well as anti-68/48 $\mathrm{kDa}$ and microtubule-associated proteone [215-217]. In addition to these increased antibody levels that are also observed in MS, patients with ME/CFS show various other markers of autoimmunity. Thus, autoantibodies against the muscarinic cholinergic receptor, mu-opioid receptor, 5-hydroxytryptamine (5-HT; serotonin) receptor $1 \mathrm{~A}$ and dopamine receptor D2 have all been detected in ME/CFS patients [218] (for a review see [9]).

Both MS and ME/CFS are also accompanied by autoimmune reactions sometimes described as secondary. These reactions are directed against neoantigenic determinants (neoepitopes), which are created as a result of 
damage to lipids and proteins by $\mathrm{O}+\mathrm{NS}[93,219]$. Thus, the organisms may mount IgM and IgG mediated autoimmune reactions against oxidatively modified epitopes, such as fatty acids or byproducts of oxidative processes (for example, azelaic acid and malondialdehyde) and nitrosatively modified proteins [93]. Antibody titers against azelaic acid are higher during acute relapses in MS [220]. Anti-oleic acid conjugated antibodies have also been found in the sera of patients with MS when in acute relapse [221]. There is also a considerable amount of direct evidence of elevated protein S-nitrosation and nitrite content together with markedly increased levels of lipid peroxidation in the serum of patients with MS $[222,223]$. Specific IgM antibodies towards NO-modified amino acids and azelaic acid and malodialdehyde have been reported in MS patients [219]. The basic principle underpinning these data is that self-epitopes may be damaged by exposure to prolonged $\mathrm{O}+\mathrm{NS}$ and thus lose their immunogenic tolerance and become a target for the hosts immune system.

The same IgM-related autoimmune responses can be detected in patients with ME/CFS, including autoimmune responses directed against disrupted lipid membrane components (palmitic, myristic and oleic acid), and residue molecules of lipid peroxidation, such as azelaic acid and malondialdehyde, IgM responses against the $S$-farnesyl-Lcysteine, and amino acids, modified by nitrating species such as nitrotyrosine, nitrophenylalanine, nitrotryptophan, nitroarginine and nitrocysteine, have all been reported [93,224]. These molecules have been damaged undergoing conformational change because of high levels of O+NS damage and have thus become immunogenic. The levels of these corrupted entities correlate positively and significantly with the severity of the ME/CFS symptoms [93].

\section{Rituximab}

The contribution of B cells to pathology in MS has been underlined by the evidence that rituximab, a monoclonal antibody that depletes CD20+ B cells in particular, has proven to be effective in the treatment of MS [225,226]. Rituximab has demonstrated efficacy in peripheral neurological diseases [227] by producing a sustained depression of pathogenic B cells [228]. In cerebrospinal fluid of MS patients, rituximab reduces not only B cells but also $T$ cells [229]. This suggests that rituximab may well have properties other than as a monoclonal antibody to $\mathrm{CD} 20+\mathrm{B}$ cells. T lymphocytes from relapsing-remitting MS patients demonstrate an impaired response to antigen stimulation following treatment with rituximab [230]. This finding supports the hypothesis that B cell activity is needed to maintain disease activity in MS $[230,231]$. The effectiveness of rituximab is not dependent on secreted antibody, as rituximab does not alter plasma cell frequencies in CSF or serum [232].
Rituximab has also some efficacy in the treatment of ME/CFS [233]. Thus, 30 patients with ME/CFS were randomized to rituximab or placebo in a placebo-controlled study and monitored for a calendar year. Positive responses were seen in $67 \%$ of the rituximab treated patients and $13 \%$ of the placebo group. The treatment improved symptoms globally. There were no serious side effects. The delayed nature of the responses (beginning from 2 to 7 months following rituximab treatment) lead the authors to conclude that ME/CFS was, at least in part, an autoimmune disease.

Rituximab is gathering momentum as a treatment in a variety of autoimmune diseases [234,235] especially where the patients are refractory to first and second line therapies [236]. When taken as a whole the trial data reveals that the vast majority of patients respond positively to rituximab. This benefit applies to people with rheumatoid arthritis [237,238], which is a licensed indication and other autoimmune conditions such as systemic lupus erythematosus [239] and Sjögren's syndrome [240] where the drug is used off license. Rituximab appears to have a number of additional benefits in addition to CD20 B cell depletion which all act to normalize immune homeostasis. Rituximab has several effects on the immune system. One of the most potentially surprising effects is the reduction of Th17 $\mathrm{T}$ cell production $[241,242]$. These $\mathrm{T}$ cells are the cause of $\mathrm{T}$ cell induced autoimmunity and neurotoxicity in autoimmune diseases such as MS. Rituximab has a direct effect on reducing IL-2 levels and thus potentially inactivating a chronically activated immune system [243]. Rituximab achieves this by inhibiting the production of $\mathrm{NFKB}[244,245]$, which is another key mediator of autoimmunity. Rituximab also raises the function of Treg cells [246,247].

\section{Summary}

Table 4 displays the similarities in B cells and autoimmune responses between MS and ME/CFS. In all, the range of autoantibodies produced in both illnesses is vast and once again virtually identical. Antibodies are found against nuclear and neuronal antigens, cardiolipin, phospholipids, serotonin, and gangliosides. IgM responses are detected against oleic, palmitic and myristic acid in patients with ME/CFS, and oleic and palmitic acid in patients with MS. Antibodies towards the byproducts of lipid peroxidation, that is, azelaic acid and MDA, and $S$ farnesyl-L-cysteine, are found in patients with ME/CFS but only towards azelaic acid and MDA in patients with MS. Autoantibodies to nitrotyrosine are found in both illnesses but a wider range of autoantibodies to other nitrated amino acids are found in ME/CFS which have not been reported in MS. This hints at the fact that O+NSinduced autoimmune responses may be higher in patients with ME/CFS than in those with MS. 


\begin{tabular}{|c|c|c|}
\hline Autoimmune responses & ED/MS & ME/CFS \\
\hline Increased numbers of B cells & $\checkmark$ & $\checkmark$ \\
\hline Anti-nuclear antibodies & $\checkmark$ & $\checkmark$ \\
\hline Anti-cardiolipin antibodies & $\checkmark$ & $\checkmark$ \\
\hline Anti-phospholipid antibodies & $\checkmark$ & $\checkmark$ \\
\hline Anti-neuronal antibodies & $\checkmark$ & $\checkmark$ \\
\hline Anti-muscle antibodies & $\checkmark$ & $\checkmark$ \\
\hline Anti-ganglioside antibodies & $\checkmark$ & $\checkmark$ \\
\hline $\begin{array}{l}\text { Anti-serotonin (5-hydroxytryptamine }(5-\mathrm{HT}) \text { ) } \\
\text { antibodies }\end{array}$ & $\checkmark$ & $\checkmark$ \\
\hline Anti-muscarinic cholinergic receptor antibodies & - & $\checkmark$ \\
\hline Anti-mu-opioid antibodies & - & $\checkmark$ \\
\hline Anti-5-HTA receptor antibodies & - & $\checkmark$ \\
\hline Anti-D2 receptor antibodies & - & $\checkmark$ \\
\hline $\begin{array}{l}\text { IgM against oxidatively modified neoepitopes, } \\
\text { for example, malondialdehyde, oleic and myristic } \\
\text { and palmitic acid }\end{array}$ & $\checkmark$ & $\checkmark$ \\
\hline $\begin{array}{l}\text { IgM against nitrosatively modified neoepitopes, } \\
\text { for example, NO adducts }\end{array}$ & $\checkmark$ & $\checkmark$ \\
\hline Response to rituximab & $\checkmark$ & $\checkmark$ \\
\hline
\end{tabular}

\section{Mitochondrial dysfunctions in MS and ME/CFS}

Many studies report changes in the levels of circulating compounds related to impaired energy metabolism, elevated $\mathrm{O}+\mathrm{NS}$, and impaired antioxidant status occurring in MS [248]. Biochemical abnormalities in levels of pyrimidines, creatine, malondialdehyde ascorbic acid, nitrate and nitrite strongly suggest a profound alteration in redox balance and energy metabolism in patients with MS [248,249]. Elevated levels of oxypurines in the serum are a product of abnormal purine nucleotide metabolism when adenosine triphosphate (ATP) production is insufficient to meet cellular demand [250,251]. Nuclear magnetic resonance imaging (NMRI) techniques allow the direct measurement of mitochondrial functioning, rate of glycolysis and availability of energy, and this approach is being increasingly used in MS research. For example, Lazzarino et al. [252] reported a significant degree of central ATP depletion in their MS patients and concluded that an increased energy demand and mitochondrial failure was the cause of that depletion. Mitochondrial damage may be driven by free radicals produced by activated microglia [253]. Damage to mitochondria and the ensuing energy failure are well known drivers for tissue injury [254]. In MS lesions, conformational changes are observed in proteins of the mitochondrial respiratory chain $[255,256]$. Deletions in mitochondrial DNA may be observed in neurons [257]. Mitochondrial DNA and proteins are both very vulnerable to damage by $\mathrm{O}+\mathrm{NS}$ [258]. Therefore, it is likely that $\mathrm{O}+\mathrm{NS}$ drive injuries to mitochondria and mitochondrial DNA in patients with MS [254,259,260].

The evidence that mitochondrial dysfunction and abnormally high lactate levels play a pivotal role in the pathophysiology of ME/CFS is expansive and expanding [261-264]. Vermeulen et al. [265] reported that in two exercise tests held $24 \mathrm{~h}$ apart, patients with ME/CFS reached their anaerobic threshold at a significantly lower oxygen consumption than healthy controls in the first test. This finding also applied to their maximal exercise capacity, which was also attained at a much lower oxygen capacity than the control group. This difference was even greater on the subsequent test. The researchers concluded that these findings demonstrated an increase in lactate production and decrease in ATP production relative to controls. Arnold et al. [266] using 31P nuclear magnetic resonance spectroscopy, revealed an abnormal increase in the level of intracellular lactic acid in the exercised forearm of a ME/CFS patient. This was proportional to concomitant changes in high-energy phosphates. Behan [261] reported finding structural mitochondrial abnormalities in the skeletal muscle of ME/CFS patients. ME/CFS patients display a significant increase in intracellular lactate levels following exercise compared to controls [263,267]. They display a significantly lower ATP resynthesis rate during recovery from exercise than normal controls stemming from impaired oxidative phosphorylation [263]. ME/CFS patients display an abnormal rise in lactate with even minor exercise and an extremely slow recovery from this state [262,263,265]. Fatigue can result from an accumulation of reactive oxygen species (ROS) and depletion of available ATP in muscle cells [268]. Patients with ME/CFS reach exhaustion at a much earlier time point than healthy controls. Upon the point of exhaustion, ME/CFS patients also have reduced intracellular levels of ATP indicating a defect of oxidative metabolism combined with an acceleration of glycolysis in the working skeletal muscles [269]. ME/CFS is accompanied by significantly increased ventricular lactate, indicating mitochondrial dysfunctions in the illness [107,270,271].

Table 5 displays the similarities in mitochondral dysfunctions between MS and ME/CFS. In all, there is considerable evidence that mitochondrial dysfunction is heavily involved in the pathophysiology of both MS and ME/CFS. Production of ATP is suboptimal and levels are depleted in the brain and/or striated muscles. Decreased phosphocreatine synthesis rates following exercise is indicative of abnormal metabolic responses to exercise in MS and ME/CFS. Impaired oxidative phosphorylation is an issue in both disorders but accelerated glycolysis in muscles has been reported in people with 


\begin{tabular}{|c|c|c|}
\hline Mitochondrial dysfunctions & ED/MS & $\mathrm{ME} / \mathrm{CFS}$ \\
\hline Depleted ATP production (muscle and brain) & $\checkmark$ & $\checkmark$ \\
\hline $\begin{array}{l}\text { Decreased phosphocreatine resynthesis } \\
\text { following exercise }\end{array}$ & $\checkmark$ & $\checkmark$ \\
\hline Impaired oxidative phosphorylation & $\checkmark$ & $\checkmark$ \\
\hline Acceleration of glycolysis & $?$ & $\checkmark$ \\
\hline $\begin{array}{l}\text { Damage to mitochondrial respiratory chain in } \\
\text { neurons }\end{array}$ & $\checkmark$ & $?$ \\
\hline Oxidative mitochondrial damage & $\checkmark$ & $\checkmark$ \\
\hline Mitochondrial energy failure & $\checkmark$ & $\checkmark$ \\
\hline \multicolumn{3}{|l|}{ Brain dysfunctions: } \\
\hline Cerebral hypoperfusion & $\checkmark$ & $\checkmark$ \\
\hline Reduced cerebral glucose metabolism & $\checkmark$ & $\checkmark$ \\
\hline Gray matter atrophy & $\checkmark$ & $\checkmark$ \\
\hline Increased cerebral lactate & $\checkmark$ & $\checkmark$ \\
\hline Increased cerebral choline & $\checkmark$ & $\checkmark$ \\
\hline Reduced levels of $\mathrm{N}$-acetyl aspartate & $\checkmark$ & $\checkmark$ \\
\hline
\end{tabular}

ME/CFS but not in people with MS. Conversely, damage to the mitochondrial respiratory chain in neurons has been reported in MS but not in ME/CFS.

\section{Brain dysfunctions}

Single photon emission computed tomography (SPECT), used to examine cerebral perfusion in MS patients, showed significant decreases in blood flow in areas of cortical gray and white matter [272,273]. Cerebral hypoperfusion in MS patients relative to controls is evident in both the cortex and deep gray matter, and is especially pronounced in the thalamus and caudate nuclei. Generalized reduction in cerebral oxygen utilization and blood flow in white and gray matter correlates with cognitive impairment [274]. Raschid et al. [275] demonstrated reduced perfusion, particularly in the gray matter of MS patients belonging to the primary and secondaryprogressive subgroups. The reduction was observed in both deep gray and cortical matter and suggests depressed neuronal metabolic activity or actual neuronal loss [275].

Patients with ME/CFS display a global reduction of brain perfusion, with a characteristic pattern of hypoperfusion in the brainstem [276,277]. SPECT abnormalities occur significantly more frequently and in greater numbers than MRI abnormalities do in patients with ME/CFS [278]. Using SPECT, a reduced cerebral blood flow was observed in the brain in $80 \%$ of ME/CFS patients [279]. Significant brain stem hypoperfusion has also been revealed in ME/ CFS patients compared to healthy controls [276,280].
Fischler et al. [277] demonstrated a positive and significant association between neurocognitive impairments experienced by patients and reduced frontal blood flow.

Positron emission tomography (PET), using a labeled native glucose analogue, that is, [18F]fludeoxyglucose (FDG-PET), has revealed a positive correlation between clinical progression of MS and cerebral glucose metabolism [281,282]. Paulasu et al. [283] reported lowered glucose metabolism in the basal ganglia and frontal cortex of MS patients reporting severe levels of fatigue. The use of FDG PET in ME/CFS has revealed glucose hypometabolism in various areas of the brain [280,284].

Traditionally 1.5 T-weighted, T1-weighted and T2weighted, non-contrast or gadolinium, and enhanced T1-weighted hyperintense MRI images have been used to monitor disease progress in the white matter of MS patients [285]. Both gray matter atrophy [285,286] and lesions $[287,288]$ have also been revealed in the cerebral cortex and deep gray matter structures using MRI. Atrophy in the brains of people with MS is related to gray matter hypointensity [289]. However, sensitivity of the conventional MRI methods for gray matter lesions is low compared to white matter lesions [288,290]. MRI techniques are not sufficiently sensitive to detect purely cortical MS lesions [291]. This sensitivity can be improved using higher field strength [292,293] or voxelbased morphometry [294,295].

MRI involving voxel-based morphometry in patients with ME/CFS has revealed gray matter volume reduction [296-298]. These reductions are apparently unrelated to the duration of illness or the age of the person examined. Subcortical white matter hyperintensities have been repeatedly recorded in ME/CFS [299,300].

The use of proton magnetic resonance spectroscopy (MRS) has revealed abnormally high levels of cerebral lactate in patients with MS [301,302]. Using choline MRS, abnormally high choline was detected in the basal ganglia of patients [303-305]. Richards [306] using MRS demonstrated elevated concentrations of choline, lactate and lipids. In another study, proton MRS revealed significantly lower $N$-acetyl aspartate levels in the hippocampal areas of MS patients [307]. MS patients with active disease have high levels of lactate levels in CSF. This elevation in lactate levels may result from anaerobic glycolysis in activated leukocytes during active disease [308].

Brooks et al. [309] examined a cohort of ME/CFS patients using MRI and nuclear MRS. Using proton MRS, significantly reduced $N$-acetyl aspartate levels were observed in the hippocampal areas of ME/CFS patients. Chaudhuri et al. [310], using the same technique, demonstrated increased choline signaling in the basal ganglia of ME/CFS patients. The choline peaks in the basal ganglia most likely are related to 'increased cell membrane turnover due reparative gliosis' [310]. In addition, Puri et al. 
[311] established a significant choline/creatine signal in the occipital cortex of patients with ME/CFS. In children with ME/CFS, significant increases in the choline/creatine ratio as measured by MRS were observed [312].

Table 5 shows the similarities in brain dysfunctions between MS and ME/CFS. In summary, using SPECT, PET, and MRI, it was found that both disorders display cerebral hypoperfusion, reduced cerebral glucose metabolism and gray matter atrophy. Nuclear MRS has revealed abnormal choline signaling in the basal ganglia in both diseases coupled with elevated levels of lactate and reduced concentrations of $N$-acetyl aspartate.

\section{Mechanistic explanations of typical ME/CFS symptoms in MS and ME/CFS}

Above, we have already discussed that many patients with MS have typical ME/CFS symptoms, including fatigue and post-exertional malaise. In this section we will discuss the mechanistic explanations of the typical symptoms of ME/ CFS that may occur in patients in MS. Fatigue in MS has both central (perception) and peripheral (impaired metabolism) components [313,314]. Figure 1 shows a diagram that integrates the numerous pathways into a mechanistic model emphasizing the shared and interactive immune signaling and metabolic pathways that explain the symptomatic similarities in both diseases.
A number of authors have suggested a role for the immunological abnormalities seen in people with MS in the production of the severe fatigue endured by so many patients. Flachenecker et al. [315] found that TNF $\alpha$ levels were significantly higher in people with fatigue than those without fatigue. Further support for this concept is found in studies that posit a mediative role for IL-6 as well as TNF $\alpha$ in the generation of fatigue in MS [316,317]. Pokryszko-Dragan et al. [318] reported that the severity of fatigue experienced by MS patients is significantly correlated to the stimulated production of IFN $\gamma$ by $\mathrm{T}$ lymphocytes. Increased levels of proinflammatory cytokines are likely involved in the development and maintenance of fatigue in MS [319]. Raised levels of O+NS and mitochondrial dysfunctions could also conspire together to cause fatigue and the post-exertional malaise experienced by people with MS $[8,128]$.

MS patients demonstrate an exaggerated metabolic response to exercise compared to controls, and thus metabolism appears to be a major contributing factor in creating the excessive muscle fatigue experienced by people with MS [320]. Patients with MS display objective and clinically significant levels of impaired functional capacity indicated by lower maximal oxygen consumption and maximal workload compared to sedentary controls. These objective abnormalities correlate positively and significantly with

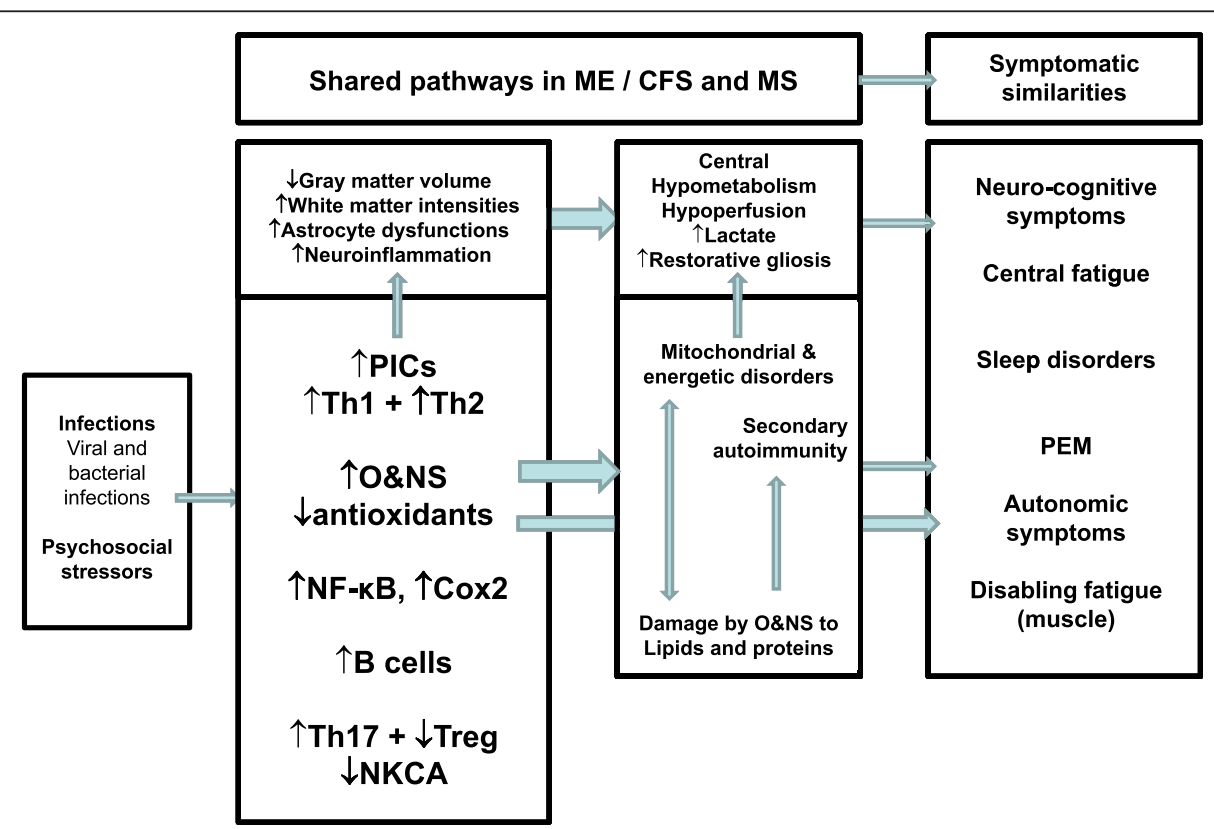

Figure 1 Diagram integrating immune signaling and metabolic pathways, which together explain the symptomatic similarities between both multiple sclerosis (MS) and myalgic encephalomyelitis/chronic fatigue syndrome (ME/CFS). Shared pathways are dysfunctions in intracellular signaling pathways, for example, nuclear factor KB (NFkB); immunoinflammatory pathways, for example, T helper (Th) and T regulatory (Treg) cells, cyclo-oxygenase 2 (COX2), and proinflammatory cytokines (PICs); and oxidative and nitrosative stress (O+NS) pathways. These in turn may induce increased damage by O+NS to proteins and lipids, secondary autoimmune responses and mitochondrial defects. There is evidence that these dysfunctions together with brain disorders are associated with the onset of ME/CFS symptoms, which appear in ME/CFS and MS. PEM = post-exertional malaise. 
measures of fatigue [321]. Fatigability of striated muscle not related to central nervous system activity is a frequent manifestation of MS [322]. In addition, it has been shown that individuals with MS have a markedly lowered rate of phosphocreatine resynthesis after depletion compared with controls [323]. The reduced phosphocreatine resynthesis results from impaired oxidative ATP production, probably stemming from impaired oxidative enzyme activities [324]. Muscle in MS patients is significantly smaller than that found in healthy individuals and relies more on anaerobic than aerobic respiration [324]. Several studies have found abnormalities relating to defects in maximal voluntary contraction during exercise or after during the facilitation period in MS patients with muscle weakness [325] and the magnitude of the defects correlates with the degree of nerve damage [326]. Motor evoked potentials (MEPs) in MS tend to be abnormal in MS if people have disabling fatigue [327,328]. Impaired motor performance has been demonstrated in people with
MS [329]. Ng et al. [330] reported that maximal voluntary contraction was $27 \%$ lower in MS patients than in the control group. The motor changes however were not related to fatigue but impaired walking ability. It is worthy of note that MS patients with a modest level of disability display gross reductions in exercise capability [331]. Savci et al. [332] noted that weakness in respiratory muscles, impaired lung function and degree of neurological impairment are not factors contributing to lowered functional exercise capability in MS patients.

Functional brain imaging research using SPECT and PET indicate that MS fatigue is connected to global glucose hypometabolism in the prefrontal cortex and the basal ganglia [282,333-336]. Other researchers [337,338] demonstrated that hypoperfusion correlates with disease and fatigue severity in MS. PET studies show that hypometabolism of particular brain areas, especially the frontal and subcortical circuits, is associated with fatigue [37,339,340]. MRI, PET and functional MRI studies

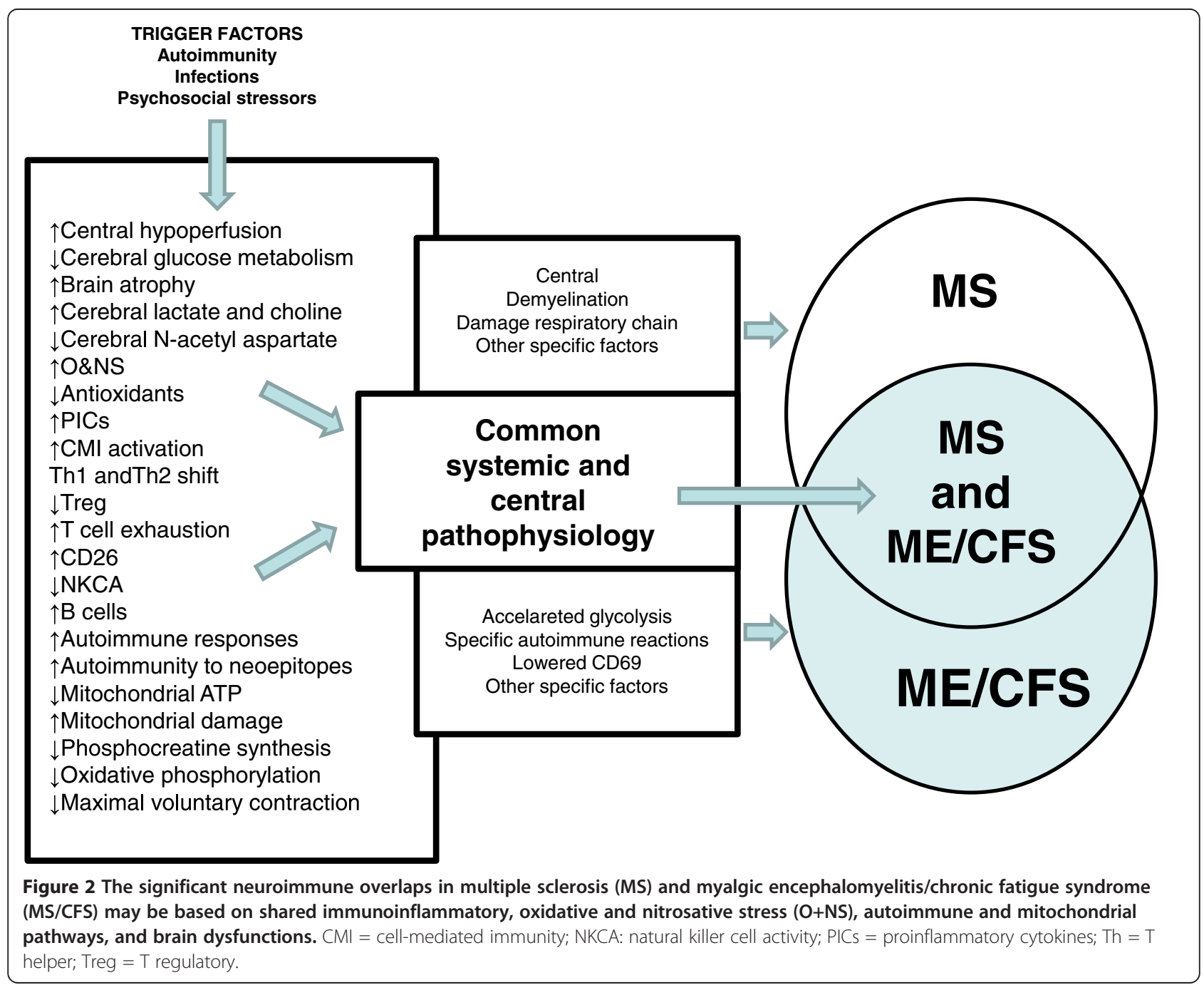




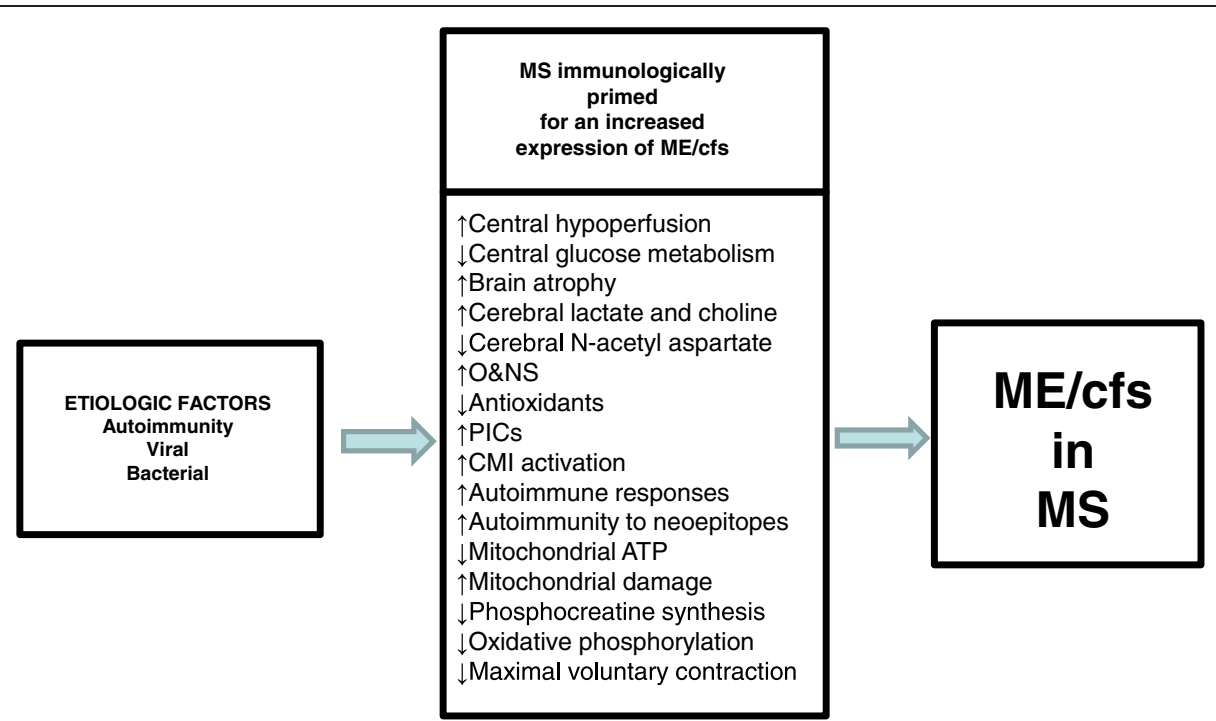

Figure 3 A second model that explains the high incidence of characteristic symptoms of myalgic encephalomyelitis/chronic fatigue syndrome (MS/CFS) in multiple sclerosis (MS). This model shows that MS patients are neuroimmunologically primed towards a higher expression of ME/CFS symptoms. Thus, the activation of immunoinflammatory, oxidative and nitrosative (O+NS), autoimmune and mitochondrial pathways, and brain dysfunctions may prime MS patients for an increased prevalence of ME/CFS symptoms. CMI = cell-mediated immunity; $\mathrm{PICs}=$ proinflammatory cytokines.

indicate that fatigue is related to gray matter disease, in the thalamus and caudate areas and particularly the cerebral cortex [341].

In addition, the fatigue, fatigability and post-exertional malaise in ME/CFS have central and peripheral components $[5,128]$. As explained elsewhere and above, fatigue in $\mathrm{ME} / \mathrm{CFS}$ is associated with and may be explained by increased levels of proinflammatory cytokines, O+NS and mitochondrial defects $[5,128]$. Several studies have found abnormalities relating to defects in maximal voluntary contraction during exercise or after during the post exercise facilitation period in ME/CFS [342]. MEP immediately following a period of exercise was significantly lower in ME/CFS and MEP facilitation 30 minutes after exercise was significantly less than in controls $[343,344]$. These parameters were also low in another study [345]. Some authors have proposed the hypothesis that the fatigue in ME/CFS is entirely of neurological origin $[346,347]$. This would however seem to be a minority viewpoint at this time.

Schillings et al. [348] reported impaired central activation in ME/CFS during maximal voluntary contraction and reported similar findings in seven out of the nine studies reviewed. Kent-Braun et al. [349] also reported markedly diminished levels of central activation at the end of a muscle contraction period. Schillings et al. [348] reported that the apparent central activation failure at maximal voluntary contraction in ME/CFS is of a similar magnitude to that reported in stroke and Amyotrophic Lateral Sclerosis [350,351]. A large number of studies demonstrate impaired motor performance in people with ME/CFS [345,352,353].

In patients with ME/CFS, Barnden et al. [297] reported that the volume of white matter, as measured using $3 \mathrm{~T}$ MRI, correlates significantly and positively with the severity of fatigue experienced by the patients. The authors noted hemodynamic abnormalities in the brainstem, deep frontal white matter, the caudal basal pons and hypothalamus, suggestive of impaired cerebrovascular autoregulation. When taken as a whole, the evidence pointed to astrocyte dysfunction and resetting of homeostatic norms. Astrocyte activity regulates cerebrovascular autoregulation [297] and cerebral blood flow $[354,355]$. Astrocyte malfunction is an important cause of mental fatigue [355]. Thus, dysfunctional astrocyte activity reported in ME/CFS would be expected to lead in a breakdown of mechanisms controlling blood flow in the brain. Patients with ME/CFS display a global reduction of brain perfusion, with a characteristic pattern of brainstem hypoperfusion $[276,356]$. The severity of disabling fatigue experienced by patients with ME/CFS is associated with the reduction in basal ganglia activation [357]. When taken as a whole, the evidence of gray matter abnormalities and astrocyte dysfunction as contributors to the fatigue experienced by those with both illnesses appears substantive.

In summary, fatigue and post-exertional malaise in MS and ME/CFS may be explained by peripheral and central mechanisms, including increased levels of proinflammatory cytokines, $\mathrm{O}+\mathrm{NS}$ and mitochondrial dysfunctions. In both 
disorders, abnormalities relating to defects in maximal voluntary contraction during exercise are detected. Central disorders, including glucose hypometabolism and cerebral hypoperfusion, may contribute to fatigue in both disorders.

\section{Summary}

MS and ME/CFS show remarkable levels of similarity in many dimensions. The ever-present disabling fatigue is a burden for both groups of patients to carry. This burden is made heavier by severe levels of exercise intolerance, which induce a worsening of symptoms in people with both illnesses. Both sets of patients resort to 'pacing' as an energy conservation strategy in an attempt to meet the energy demands associated with normal living. ME/ CFS and MS are more prevalent in women than in men and show a chronic or waxing and waning course. Increased levels of $\mathrm{O}+\mathrm{NS}$ occur in both illnesses and patients share an almost identical range of empirically determined abnormalities as evidenced by elevated levels of peroxinitrite, $\mathrm{NO}$ and iNOS, lipid peroxidation and nitration of amino acids. The consequences of $\mathrm{O}+\mathrm{NS}$ damage to self-epitopes is evidenced by the almost bewildering and almost identical array of autoantibodies formed against damaged epitopes seen in both illnesses. Reduced levels of antioxidants, including vitamin E, zinc, glutathione are also found in both diseases. Evidence of chronic immune activation coupled with disordered $\mathrm{T}$ cell homeostasis is seen in both diseases. Similar abnormalities exist in levels of proinflammatory cytokines, serum neopterin and $\mathrm{T}$ cell antigens. Although reduced NKC function in ME/CFS has been emphasized over many years the identical abnormalities in MS has not received such widespread attention. The findings produced by neuroimaging using PET, SPECT and nuclear MRS are similar in both illnesses and in MS the severity of the abnormality in glucose metabolism correlates well with disease activity while MRI findings do not.

There are however also differences in symptomatic and immune profiles between both diagnoses. Thus, patients with ME/CFS seem more sensitive to increases in physical or cognitive activity than patients with MS. ME/ CFS patients may have a worse experience with regard to infections, while the number of infections is associated with increasing symptom severity. While MS is characterized by increased expression of CD69, a decreased CD69 expression is seen in ME/CFS. Accelerated glycolysis is reported in ME/CFS but not in MS. Neuronal damage to the respiratory chain has been found in MS but not in ME/CFS. T cell exhaustion seems to be more of an issue in ME/CFS than in MS. When taken together the range of surrogate markers for $\mathrm{O}+\mathrm{NS}$ and the range of autoantibodies are wider in ME/ CFS than in MS and this may be due to an increased severity of $\mathrm{O}+\mathrm{NS}$ in $\mathrm{ME} / \mathrm{CFS}$. While coenzyme Q10 is related to fatigue in ME/CFS, the findings in MS are less evident. Finally, while both ME/CFS and MS are chronic immunoinflammatory diseases, inflammation of the central nervous system is clearly more prominent in MS than in ME/CFS.

Nevertheless, the strong similarities between both disorders in terms of phenomenological, neurobehavior and neuroimmune characteristics further underscore that ME/CFS belongs to the spectrum of neuroimmune disorders. In addition, the data show that the comorbidity between both disorders and the high prevalence of ME/ CFS symptoms in patients with MS may be explained by neuroimmune mechanisms.

Figure 2 shows that the significant comorbidity between MS and ME/CFS may be based on shared immunoinflammatory, $\mathrm{O}+\mathrm{NS}$, autoimmune and mitochondrial pathways and brain dysfunctions.

Figure 3 shows a second model that explains the high incidence of typical ME/CFS symptoms in patients with MS. This model suggests that patients with MS are neurologically and immunologically primed for an increased expression of ME/CFS symptoms. Thus, the activation of immunoinflammatory, autoimmune, mitochondrial and $\mathrm{O}+\mathrm{NS}$ pathways together with brain disorders may prime MS patients for an increased prevalence of ME/CFS symptoms. Other possibilities are that ME/CFS could increase the odds to develop MS or when comorbid with MS could aggravate the severity of MS. It is also possible that there is a junction in immunoinflammatory progression that could explain bifurcation to ME/CFS rather than MS. For example, the initial lesions in ME/CFS could be smaller than in MS but at the expense of greater bioenergetic impairments [5].

\section{Abbreviations}

COX2: Cyclo-oxygenase 2; CSF: Cerebrospinal fluid; DPPIV: Dipeptidyl peptidase 4; FDG: Fluodeoxyglucose; HR: Heart rate; IFN: Interferon; IL: Interleukin; iNOS: Inducible nitric oxide synthase; ME/CFS: Myalgic encephalomyelitis/chronic fatigue syndrome; MEP: Motor evoked potentials; MRI: Magnetic resonance imaging; MRS: Magnetic resonance spectroscopy; MS: Multiple sclerosis; NFKB: Nuclear factor KB; NKCA: Natural killer cell activity; NMRI: Nuclear magnetic resonance imaging; NO: Nitric oxide; O+NS: Oxidative and nitrosative stress; PD: Programmed death; PET: Positron emission tomography; POTS: Postural orthostatic tachycardia syndrome; ROS: Reactive oxygen species; SPECT: Single photon emission computed tomography; TGF: Transforming growth factor; Th: T helper; TNF: Tumor necrosis factor; Treg: T regulatory.

\section{Competing interests}

No specific funding was obtained for this review. The authors declare that they have no competing interests.

\section{Authors' contributions}

GM and MM participated in the design of this review and contributed equally to this paper. All authors read and approved the final version.

\section{Author details}

${ }^{1}$ Tir Na Nog, Pembrey, Llanelli, UK. ²Department of Psychiatry, Chulalongkorn University, Bangkok, Thailand. ${ }^{3}$ Department of Psychiatry, Deakin University, Geelong, Australia. 
Received: 16 June 2013 Accepted: 15 August 2013

Published: 17 September 2013

\section{References}

1. Disanto G, Berlanga AJ, Handel AE, Para AE, Burrell AM, Fries A, Handunnetthi L, De Luca GC, Morahan JM: Heterogeneity in multiple sclerosis: scratching the surface of a complex disease. Autoimm Dis 2010, 2011:932351.

2. Huang YM, Liu X, Steffensen K, Sanna A, Arru G, Fois ML, Rosati G, Sotgiu S, Link H: Immunological heterogeneity of multiple sclerosis in Sardinia and Sweden. Mult Scler 2005, 11:16-23.

3. Hohlfeld $\mathrm{R}$, Wekerle $\mathrm{H}$ : Autoimmune concepts of multiple sclerosis as a basis for selective immunotherapy: from pipe dreams to (therapeutic) pipelines. Proc Natl Acad Sci U S A 2004, 2004:14599-14606.

4. Winkler AS, Blair D, Marsden JT, Peters TJ, Wessely S, Cleare AJ: Autonomic function and serum erythropoietin levels in chronic fatigue syndrome. J Psychosom Res 2004, 56:179-183.

5. Morris G, Maes M: A neuro-immune model of myalgic encephalomyelitis/ chronic fatigue syndrome. Metab Brain Dis 2012. Epub ahead of print.

6. Morris G, Anderson G, Galecki P, Berk M, Maes M: A narrative review on the similarities and dissimilarities between myalgic encephalomyelitis/ chronic fatigue syndrome (ME/CFS) and sickness behavior. BMC Med 2013, 11:64

7. Sharpe MC, Archard LC, Banatvala JE, Borysiewicz LK, Clare AW, David A Edwards RH, Hawton KE, Lambert HP, Lane RJ: A report-chronic fatigue syndrome: guidelines for research. J R Soc Med 1991, 84:118-121.

8. Morris G, Maes M: Case definitions and diagnostic criteria for myalgic encephalomyelitis and Chronic fatigue Syndrome: from clinicalconsensus to evidence-based case definitions. Neuro Endocrinol Lett 2013, 34:185-199.

9. Maes M: Nooit meer moe: CVS ontmaskerd. Brugge, Belgium: Zorro Uitgevers; 2010.

10. Maes M, Twisk FN, Johnson C: Myalgic encephalomyelitis (ME), chronic fatigue syndrome (CFS), and chronic fatigue (CF) are distinguished accurately: Results of supervised learning techniques applied on clinical and inflammatory data. Psychiatr Res 2012, 200:754-760.

11. Carruthers BM, van de Sande MI, De Meirleir KL, Klimas NG, Broderick G, Mitchell T, Staines D, Powles AC, Speight N, Vallings R, Bateman L, Baumgarten-Austrheim B, Bell DS, Carlo-Stella N, Chia J, Darragh A, Jo D, Lewis D, Light AR, Marshall-Gradisbik S, Mena I, Mikovits JA, Miwa K, Murovska M, Pall ML, Stevens S: Myalgic encephalomyelitis: international consensus criteria. J Intern Med 2011, 270:327-338.

12. Freeman $\mathrm{R}$, Komaroff $\mathrm{AL}$ : Does the chronic fatigue syndrome involve the autonomic nervous system? Am J Med 1997, 102:357-364.

13. Allen J, Murrary A, Di Maria C, Newton JL: Chronic fatigue syndrome and impaired peripheral pulse characteristics on orthostasis - a new potential diagnostic biomarker. Physiol Meas 2010, 33:231-241.

14. Newton JL, Okonkwo O, Sutcliffe K, Seth A, Shin J, Jones DEJ: Symptoms of autonomic dysfunction in chronic fatigue syndrome. Q J Med 2007, 100:519-526.

15. Mosqueda Garcia R, Furlan R, Snell M, Jacob G, Harris P: Primary sympathetic hyperadrenergic orthostatic tachycardia syndrome (HOT). Neurology 1997, 48:A147.

16. Montague TJ, Marrie TJ, Klassen GA, Bewick DJ, Horacek BM: Cardiac function at rest and with exercise in the chronic fatigue syndrome. Chest 1989, 95:779-784.

17. Pagani M, Lucini D, Mela GS, Langewitz W, Malliani A: Sympathetic overactivity in subjects complaining of unexplained fatigue. Clin Sci 1994, 87:655-661

18. De Becker P, Dendale P, De Meirleir K, Campine I, Vandenborne K, Hagers Y: Autonomic testing in patients with chronic fatigue syndrome. Am J Med 1998, 105:122S-126S

19. Soetekouw PM, Lenders JW, Bleijenberg G, Thien T, van der Meer JW: Autonomic function in patients with chronic fatigue syndrome. Clin Auton Res 1999, 9:334-340.

20. Rowe PC, Boo-Holaigh I, Kan JS, Calkins H: Is neurally mediated hypotension an unrecognized cause of chronic fatigue? Lancet 1995, 345:623-624.

21. Bou-Holaigh I, Rowe PC, Kan JS, Calking H: The relationship between neurally mediated hypotension and the chronic fatigue syndrome. JAMA 1995, 274:961-967.
22. Streeten $\mathrm{DH}$, Anderson $\mathrm{GH}$ Jr: The role of delayed orthostatic hypotension in the pathogenesis of chronic fatigue. Clin Auton Res 1998, 8:119-124.

23. Schondorf $R$, Freeman $R$ : The importance of orthostatic intolerance in the chronic fatigue syndrome. Am J Med Sci 1999, 317:117-123.

24. Axelrod FB, Chelimsky GG, Weese-Mayer DE: Pediatric autonomic disorders. Pediatrics 2006, 2006:309-321.

25. Stewart J, Weldon A, Arlievsky N, Li K, Munoz J: Neurally mediated hypotension and autonomic dysfunction measured by heart rate variability during head-up tilt table testing in children with chronic fatigue syndrome. Clin Auton Res 1998, 8:221-230.

26. Stewart JM, Gewitz MH, Weldon A, Munoz J: Patterns of orthostatic intolerance: the orthostatic tachycardia syndrome and adolescent chronic fatigue. J Pediatr 1999, 135:218-225.

27. Stewart JM: Autonomic nervous system dysfunction in adolescents with postural orthostatic tachycardia syndrome and chronic fatigue syndrome is characterized by attenuated vagal baroreflex and potentiated sympathetic vasomotion. Pediatr Res 2000, 48:218-226.

28. Shepherd C: Pacing and exercise in chronic fatigue syndrome. Physiotherapy 2001, 87:395-396

29. Iriarte J, de Castro P: Correlation between sympotom fatigue and muscular fatigue in multiple sclerosis. Eur J Neurol 1998, 5:579-585.

30. Barak $Y$, Achiron A: Cognitive fatigue in multiple sclerosis: findings from a two-wave screening project. J Neurol Sci 2006, 245:73-76.

31. Iriarte J, Subira ML, Castro P: Modalities of fatigue in multiple sclerosis: correlation with clinical and biological factors. Mult Scler 2000, 6:124-130.

32. Olsson M, Lexell J, Soderberg S: The meaning of fatigue for women with multiple sclerosis. J Adv Nurs 2005, 49:7-15.

33. Kos D, Kerckhofs E, Nagels G, D'hooghe B, Ilsbroukx S: Origin of fatigue in multiple sclerosis: review of the literature. Neurorehabil Neural Repair 2007, 20:1-10.

34. Vucic S, Burke D, Kiernan MC: Fatigue in multiple sclerosis: mechanisms and management. Clin Neurophysiol 2010, 121:809-817.

35. Boerio D, Lefaucheur JP, Hogrel JY, Creange A: Pathophysiology and treatment of fatigue in multiple sclerosis. Rev Neurol 2006, 162:311-320.

36. Debouverie M, Pittion S: Fatigue and episodic exhaustion as a feature of multiple sclerosis. Rev Neurol 2006, 162:295-297.

37. Bakshi R: Fatigue associated with multiple sclerosis: diagnosis, impact and management. Mult Scler 2003, 9:219-227.

38. Haensch CA, Jorg J: Autonomic dysfunction in multiple sclerosis. J Neurol 2006, 253:13-19.

39. Lensch $\mathrm{E}$, Jost $\mathrm{WH}$ : Autonomic disorders in multiple sclerosis. Autoimmune Dis 2011, 2011:803841.

40. Kanjwal K, Karabin B, Kanjwal Y, Grubb BP: Autonomic dysfunction presenting as postural orthostatic tachycardia syndrome in patients with multiple sclerosis. Int J Med Sci 2010, 7:62-67.

41. McDougall J, McLeod JG: Autonomic nervous system function in multiple sclerosis. J Neurol Sci 2003, 215:79-85.

42. Merkelbach U, Dillmann C, Kolmel J, Holz I, Muller M: Cardiovascular autonomic dysregulation and fatigue in multiple sclerosis. Mult Scler 2001, 7:320-326

43. de Seze J, Stojkovic T, Gauvrit JY, Devos D, Ayachi M, Cassim F, Saint Michel T, Pruvo JP, Guieu JD, Vermersch P: Autonomic dysfunction in multiple sclerosis: cervical spinal cord atrophy correlates. J Neurol 2001, 248:297-303.

44. Nordenbo AM, Boesen F, Andersen EB: Cardiovascular autonomic function in multiple sclerosis. J Auton Nerv Syst 1989, 26:77-84

45. Mathiowetz VG, Finlayson ML, Matuska KM, Chen HY, Luo P: Randomized trial of an energy conservation course for persons with multiple sclerosis. Mult Scler 2005, 11:592-601.

46. Matuska K, Mathiowetz V, Finlayson M: Use and perceived effectiveness of energy conservation strategies for managing multiple sclerosis fatigue. Am J Occup Ther 2007, 61:62-69.

47. Vanage SM, Gilbertson KK, Mathiowetz V: Effects of energy conservation course on fatigue impact for persons with progressive multiple sclerosis. Am J Occup Ther 2003, 57:315-323.

48. Papanicolaou DA, Amsterdamb JD, Levine S, McCann SM, Moore RC, Newbrand CH, Allen G, Nisenbaum R, Pfaff DW, Tsokos GC, Vgontzas AN, Kales A: Neuroendocrine Aspects of chronic fatigue syndrome. Neuroimmunomodulation 2003, 11:65-74.

49. Reynolds NL, Brown MM, Jason LA: The relationship of Fennell phases to symptoms among patients with chronic fatigue syndrome. Eval Health Prof 2009, 32:264-280. 
50. Nisenbaum R, Jones JF, Unger ER, Reyes M, Reeves WC: A populationbased study of the clinical course of chronic. Health Qual Life Outcomes 2003, 1:49

51. Fukuda K, Straus SE, Hickie I, Sharpe MC, Dobbins JG, Komaroff A: The chronic fatigue syndrome: a comprehensive approach to its definition and study. International Chronic Fatigue Syndrome Study Group. Ann Intern Med 1994, 121:953-959.

52. Hinds GME, McCluskey DR: A retrospective study of chronic fatigue syndrome. Proc R Coll Physicians Edinburgh 1993, 23:10-14.

53. Wilson A, Hickie I, Lloyd A, Hadzi-Pavlovic D, Boughton C, Dwyer J, Wakefield D: Longitudinal study of outcome of chronic fatigue syndrome. Br Med J 1994, 308:756759.

54. Tiersky LA, DeLuca J, Hill N, Dhar SK, Johnson SK, Lange G, Rappolt G, Natelson BH: Longitudinal assessment of neuropsychological functioning, psychiatric status, functional disability and employment status in chronic fatigue syndrome. Appl Neuropsychol 2001, 8:41-50.

55. Hill NF, Tiersky LA, Scavalla VR, Lavietes M, Natelson BH: Natural history of severe chronic fatigue syndrome. Arch Phys Med Rehabil 1999, 80:1090-1094.

56. Van der Werf SP, de Vree B, Alberts M, Van der Meer JWM, Bleijenberg G: Natural course and predicting self- reported improvement in patients with chronic fatigue syndrome with a relatively short illness duration. J Psychosomat Res 2002, 53:749753.

57. Peterson PK, Schenck CH, Sherman R: Chronic fatigue syndrome in Minnesota. Minn Med 1991, 74:21-26.

58. Saltzstein BJ, Wyshak G, Hubbuch JT, Perry JC: A naturalistic study of the chronic fatigue syndrome among women in primary care. Gen Hosp Psychiatry 1998, 20:307316.

59. Buljevac D, Flach HZ, Hop WC, Hijdra D, Laman JD, Savelkoul HF, van Der Meche FG, van Doorn PA, Hintzen RQ: Prospective study on the relationship between infections and multiple sclerosis exacerbations. Brain 2002, 125:952-960

60. Buljevac D, Hop WC, Reedeker W, Janssens AC, van der Meche FG, van Doorn PA, Hintzen RQ: Self reported stressful life events and exacerbations in multiple sclerosis: prospective study. BMJ 2003, 327:646.

61. Persoons JH, Schornagel K, Breve J, Berkenbosch F, Kraal G: Acute stress affects cytokines and nitric oxide production by alveolar macrophages differently. Am J Respir Crit Care Med 1995, 152:619-624.

62. Ontaneda D, Rae-Grant A: Management of acute exacerbations in multiple sclerosis. Ann Indian Acad Neurol 2009, 12:264-272.

63. Nicolson GL, Nasralla M, Haier J, Erwin R, Nicolson NL, Ngwenya R: Mycoplasmal infections in chronic illnesses: fibromyalgia and chronic fatigue syndromes, Gulf War illness, HIV-AIDS and rheumatoid arthritis. Med Sentinel 1999, 4:172-176.

64. Nicolson GL, Haier J, Nasralla M, Haier J, Erwin R, Nicolson NL, Ngwenya R: Mycoplasmal infections in chronic fatigue syndrome, fibromyalgia syndrome and Gulf War illness. JCFS 2000, 6:23-39.

65. Nicolson GL, Nasralla M, De Meirleir K, Gan R, Haier J: Evidence for bacterial (Mycoplasma, Chlamydia) and viral (HHV-6) co-infections in chronic fatigue syndrome patients. JCFS 2003, 11:7-20.

66. Nicolson GL, Gan R, Haier J: Multiple co-infections (Mycoplasma, Chlamydia, human herpesvirus-6) in blood of chronic fatigue syndrome patients: association with signs and symptoms. APMIS 2003, 111:557-566.

67. Nicolson GL, Nicolson NL, Haier J: Chronic fatigue syndrome patients subsequently diagnosed with Lyme Disease Borrelia burgdorferi: evidence for mycoplasma species co-infections. JCFS 2008, 14:5-17.

68. Vojdani A, Choppa PC, Tagle C, Andrin R, Samimi B, Lapp CW: Detection of mycoplasma genus and mycoplasma fermentans by PCR in patients with chronic fatigue syndrome. FEMS Immunol Med Microbiol 1998, 22:355-365

69. Seishima M, Mizutani Y, Shibuya Y, Arakawa C: Chronic fatigue syndrome after human parvovirus B19 infection without persistent viremia. Dermatology 2008, 216:341-346.

70. Chia JK, Chia AY: Chronic fatigue syndrome is associated with chronic enterovirus infection of the stomach. J Clin Pathol 2008, 61:43-48.

71. Goudsmit EM, Howes S: Pacing to manage chronic fatigue syndrome. Pacing: an additional strategy to manage fatigue in chronic fatigue syndrome. http://freespace.virgin.net/david.axford/pacing.htm.

72. LaManca JJ, Peckerman A, Sisto SA, DeLuca J, Cook S, Natelson BH: Cardiovascular responses of women with chronic fatigue syndrome to stressful cognitive testing before and after strenuous exercise. Psychosom Med 2001, 63:756-764.
73. Kerr JR, Mattey DL: Preexisting psychological stress predicts acute and chronic fatigue and arthritis following symptomatic parvovirus B19 infection. Clin Infect Dis 2008, 46:e83-e87.

74. Ebers GC: Environmental factors and multiple sclerosis. Lancet Neurol 2008, 7:268-277

75. Simpson S Jr, Blizzard L, Otahal P, Van der Mei I, Taylor B: Latitude is significantly associated with the prevalence of multiple sclerosis: a meta-analysis. J Neurol Neurosurg Psychiatry 2011, 82:1132-1141.

76. Buchwald D, Umali P, Umali J, Kith P, Pearlman T, Komaroff AL: Chronic fatigue and the chronic fatigue syndrome: prevalence in a Pacific Northwest health care system. Ann Intern Med 1995, 123:81-88.

77. Acheson D: The clinical syndrome variously called benign myalgic encephalomyelitis, Iceland disease and epidemic neuromyasthenia. Am J Med 1959, 26:569-595.

78. Holmes GP, Kaplan JE, Gantz NM, Komaroff AL, Schonberger LB, Straus SE, Jones JF, Dubois RE, Cunningham-Rundles C, Pahwa S, Tosato G, Zegans LS, Purtilo DT, Brown N, Schooley RT, Brus I: Chronic fatigue syndrome: a working case definition. Ann Intern Med 1988, 108:387-389.

79. Jason LA, King CP, Frankenberry EL, Jordan KM, Tryon WW, Rademaker F, Huang CF: Chronic fatigue syndrome: assessing symptoms and activity level. J Clin Psychol 1999, 55:411-424.

80. Reyes M, Nisenbaum R, Hoaglin DC, Unger ER, Emmons C, Randall B, Stewart JA, Abbey S, Jones JF, Gantz N, Minden S, Reeves WC: Prevalence and incidence of chronic fatigue syndrome in Wichita. Kansas. Arch Intern Med 2003, 2003:1530-1536

81. Harbo HF, Gold R, Tintore M: Sex and gender issues in multiple sclerosis. Ther Adv Neurol Disord 2013, 6:237-248.

82. Haider L, Fischer MT, Frischer JM, Bauer J, Hoftberger R, Botond G, Esterbauer $\mathrm{H}$, Binder $\mathrm{CJ}$, Witztum $J \mathrm{~L}$, Lassmann $\mathrm{H}$ : Oxidative damage in multiple sclerosis lesions. Brain 2011, 134:1914-1924.

83. Gonsette RE: Review: Oxidative stress and excitotoxicity: a therapeutic issue in multiple sclerosis? Mult Scler 2008, 14:22-34.

84. Toshniwal PK, Zarling EJ: Evidence for increased lipid peroxidation in multiple sclerosis. Neurochem Res 1992, 17:205-207.

85. van Horssen J, Schreibelt G, Drexhage J, Hazes T, Dijkstra CD, van der Valk P, de Vries HE: Severe oxidative damage in multiple sclerosis lesions coincides with enhanced antioxidant enzyme expression. Free Radic Biol Med 2008, 45:1729-1737.

86. Smith KJ, Kapoor R, Felts A: Demyelination: the role of reactive oxygen and nitrogen species. Brain Pathol 1999, 9:69-92.

87. Hill KE, Zollinger LV, Watt HE, Carlson NG, Rose JW: Inducible nitric oxide synthase in chronic active multiple sclerosis plaques: distribution, cellular expression and association with myelin damage. J Neuroimmunol 2004, 151:171-179.

88. Koch M, Mostert J, Arutjunyan A, Stepanov M, Teelken A, Heersema D, De Keyser J: Peripheral blood leukocyte NO production and oxidative stress in multiple sclerosis. Mult Scler 2008, 14:159-165.

89. Basu S: Isoprostanes: novel bioactive products of lipid peroxidation. Free Radic Res 2004, 38:105-122.

90. Greco A, Minghetti L, Levi G: Isoprostanes, novel markers of oxidative injury, help understanding the pathogenesis of neurodegenerative diseases. Neurochem Res 2000, 25:1357-1364.

91. Morrow JD: The isoprostanes - unique products of arachidonate peroxidation: their role as mediators of oxidant stress. Curr Pharm 2006, 12:895-902.

92. Mattsson N, Haghighi S, Andersen O, Yao Y, Rosengren L, Blennow K, Pratico D, Zetterberg $\mathrm{H}$ : Elevated cerebrospinal fluid F2- isoprostane levels indicating oxidative stress in healthy siblings of multiple sclerosis patients. Neurosci Lett 2007, 414:233-236.

93. Maes M, Mihaylova I, Leunis JC: Chronic fatigue syndrome is accompanied by an IgM-related immune response directed against neopitopes formed by oxidative or nitrosative damage to lipids and proteins. Neuro Endocrinol Lett 2006, 27:615-621.

94. Maes M, Mihaylova I, Kubera M, Uytterhoeven M, Vrydags $N$, Bosmans E: Increased 8-hydroxy-deoxyguanosine, a marker of oxidative damage to DNA, in major depression and myalgic encephalomyelitis/chronic fatigue syndrome. Neuro Endocrinol Lett 2009, 30:715-722.

95. Maes M, Mihaylova I, Kubera M, Uytterhoeven M, Vrydags N, Bosmans E: Coenzyme Q10 deficiency in myalgic encephalomyelitis/chronic fatigue syndrome (ME/CFS) is related to fatigue, autonomic and neurocognitive symptoms and is another risk factor explaining the early mortality in 
ME/CFS due to cardiovascular disorder. Neuro Endocrinol Lett 2009 30:470-476.

96. Maes M, Kubera M, Uytterhoeven M, Vrydags N, Bosmans E: Increased plasma peroxides as a marker of oxidative stress in myalgic encephalomyelitis/chronic fatigue syndrome (ME/CFS). Med Sci Monit 2011, 17:SC11-SC15.

97. Manuel y Keenoy B, Moorkens G, Vertommen J, Noe M, Neve J, De Leeuw I: Magnesium status and parameters of the oxidant-antioxidant balance in patients with chronic fatigue: effects of supplementation with magnesium. J Am Coll Nutr 2000, 19:374-382.

98. Manuel-y-Keenoy B, Moorkens G, Vertommen J, De Leeuw I: Antioxidant status and lipoprotein peroxidation in chronic fatigue syndrome. $\mathrm{Life} S \mathrm{SC}$ 2001, 68:2037-2049.

99. Vecchiet J, Cipollone F, Falasca K, Mezzetti A, Pizzigallo E, Bucciarelli T, De Laurentis S, Affaitati G, De Cesare D, Giamberardino MA: Relationship between musculoskeletal symptoms and blood markers of oxidative stress in patients with chronic fatigue syndrome. Neurosci Letters 2003, 335:151-154.

100. Miwa K, Fujita M: Fluctuation of serum vitamin E (alpha-tocopherol) concentrations during exacerbation and remission phases in patients with chronic fatigue syndrome. Heart Vessels 2010, 25:319-323.

101. Kennedy G, Spence VA, McLaren M, Hill A, Underwood C, Belch JJ: Oxidative stress levels are raised in chronic fatigue syndrome and are associated with clinical symptoms. Free Radic Biol Med 2005, 39:584-589.

102. Maes M, Mihaylova I, Kubera M, Bosmans E: Not in the mind but in the cell: increased production of cyclo-oxygenase- 2 and inducible NO synthase in chronic fatigue syndrome. Neuro Endocrinol Lett 2007, 28:463-469.

103. Jammes Y, Steinberg JG, Delliaux S: Chronic fatigue syndrome: acute infection and history of physical activity affect resting levels and response to exercise of plasma oxidant/antioxidant status and heat shock proteins. J Intern Med 2011, 272:74-84.

104. Jammes Y, Steinberg JG, Mambrini O, Bregeon F, Delliaux S: Chronic fatigue syndrome: assessment of increased oxidative stress and altered muscle excitability in response to incremental exercise. J Intern Med 2005, 257:299-310.

105. Fulle S, Pietrangelo T, Mancinelli R, Saggini R, Fano G: Specific correlations between muscle oxidative stress and chronic fatigue syndrome: a working hypothesis. J Muscle Res Cell Motil 2007, 28:355-362.

106. Richards RS, Roberts TK, McGregor NR, Dunstan RH, Butt HL: Blood parameters indicative of oxidative stress are associated with symptom expression in chronic fatigue syndrome. Redox Rep 2000, 5:35-41.

107. Shungu DC, Weiduschat N, Murrough JW, Mao X, Pillemer S, Dyke JP, Medow MS, Natelson BH, Stewart JM, Mathew SJ: Increased ventricular lactate in chronic fatigue syndrome. III. Relationships to cortical glutathione and clinical symptoms implicate oxidative stress in disorder pathophysiology. NMR Biomed 2012, 25:1073-1087.

108. Syburra C, Passi S: Oxidative stress in patients with multiple sclerosis. Ukr Biokhim Zh 1999, 71:112-115.

109. de Bustos F, Jiménez-Jiménez FJ, Molina JA, Gómez-Escalonilla $C$, de Andrés C, del Hoyo P, Zurdo M, Tallón-Barranco A, Berbel A, Porta-Etessam J, Parrilla $\mathrm{G}$, Arenas J: Serum levels of coenzyme Q10 in patients with multiple sclerosis. Acta Neurol Scand 2000, 101:209-211.

110. Choi IY, Lee SP, Denney DR, Lynch SG: Lower levels of glutathione in the brains of secondary progressive multiple sclerosis patients measured by $1 \mathrm{H}$ magnetic resonance chemical shift imaging at 3 T. Mult Scler 2011, 17:289-296.

111. Ghazavi A, Kianbakht S, Ghasami K, Mosayebi G: High copper and low zinc serum levels in Iranian patients with multiple sclerosis: a case control study. Clin Lab 2012, 58:161-164.

112. Maes M, Mihaylova I, Leunis JC: In chronic fatigue syndrome, the decreased levels of omega-3 poly-unsaturated fatty acids are related to lowered serum zinc and defects in T cell activation. Neuro Endocrinol Lett 2005, 26:745-751.

113. Dujmovic I, Mangano K, Pekmezovic T, Quattrocchi C, Mesaros S, Stojsavljevic N, Nicoletti F, Drulovic J: The analysis of IL-1 beta and its naturally occurring inhibitors in multiple sclerosis: the elevation of IL-1 receptor antagonist and IL-1 receptor type II after steroid therapy. J Neuroimmunol 2009, 207:101-106.

114. Argaw AT, Zhang Y, Snyder BJ, Zhao ML, Kopp N, Lee SC, Raine CS, Brosnan CF, John GR: IL-1beta regulates blood-brain barrier permeability via reactivation of the hypoxia-angiogenesis program. J Immunol 2006, 177:5574-5584.

115. Hauser SL, Doolittle TH, Lincoln R, Brown RH, Dinarello CA: Cytokine accumulations in CSF of multiple sclerosis patients: frequent detection of interleukin-1 and tumor necrosis factor but not interleukin-6. Neurology 1990, 40:1735-1739.

116. Sharief MK, Hentges R: Association between tumor necrosis factor-alpha and disease progression in patients with multiple sclerosis. N Engl J Med 1991, 325:467-472

117. Al-Omaishi J, Bashir R, Gendelman HE: The cellular immunology of multiple sclerosis. J Leukoc Biol 1999, 65:444-452.

118. Frei K, Fredrikson S, Fontana A, Link H: Interleukin-6 is elevated in plasmain multiple sclerosis. J Neuroimmunol 1991, 31:147-153.

119. Carrieri PB, Provitera V, De Rosa T, Tartaglia G, Gorga F, Perrella O: Profile of cerebrospinal fluid and serum cytokines in patients with relapsingremitting multiple sclerosis. A correlation with clinical activity. Immunopharmacol Immunotoxicol 1998, 20:373-382.

120. Gajewski TF, Schell SR, Nau G, Fitch FW: Regulation of T-cell activation: differences among T-cell subsets. Immunol Rev 1989, 111:79-110.

121. Murphy KM, Reiner SL: The lineage decisions of helper T cells. Nat Rev Immunol 2002, 2002:933-944.

122. Imam SA, Guyton MK, Haque A, Vandenbark A, Tyor WR, Ray SK, Banik NL: Increased calpain correlates with Th1 cytokine profile in PBMCs from MS patients. J Neuroimmunol 2007, 190:139-145.

123. Koguchi K, Anderson DE, Yang L, O'Connor KC, Kuchroo VK, Hafler DA: Dysregulated T cell expression of TIM3 in multiple sclerosis. J Exp Med 2006, 203:1413-1418.

124. Cannella B, Raine CS: The adhesion molecule and cytokine profile of MS lesions. Ann Neurol 1995, 37:424-435.

125. Navikas V, Link H: Cytokines and the pathogenesis of multiple sclerosis. J Neurosci Res 1996, 45:322-333.

126. Rodriguez-Sainz Mdel C, Sanchez-Ramon S, de Andres C, Rodriguez-Mahou M, Munoz-Fernandez MA: Th1/Th2 cytokine balance and nitric oxide in cerebrospinal fluid and serum from patients with multiple sclerosis. Eur Cytokine Netw 2002, 13:110-114.

127. Maes M, Twisk FNM, Kubera M, Ringel K: Evidence for inflammation and activation of cell-mediated immunity in myalgic encephalomyelitis/ chronic fatigue syndrome (ME/CFS): increased interleukin-1, tumor necrosis factor-a, PMN-elastase, lysozyme and neopteri. J Affect Disord 2012, 136:933-939.

128. Morris G, Maes M: Increased nuclear factor-kB and loss of p53 are key mechanisms in myalgic encephalomyelitis/chronic fatigue syndrome (ME/CFS). Med Hypotheses 2012, 79:607-613.

129. Maher KJ, Klimas NG, Fletcher MA: Chronic fatigue syndrome is associated with diminished intracellular perforin. Clin Exp Immunol 2005, 142:505-511.

130. Broderick G, Fuite J, Kreitz A, Vernon SD, Klimas N, Fletcher MA: A formal analysis of cytokine networks in chronic fatigue syndrome. Brain Behav Immun 2010, 24:1209-1217.

131. Rose JW, Hill KE, Watt HE, Carlson NG: Inflammatory cell expression of cyclooxygenase-2 in the multiple sclerosis lesion. J Neuroimmunol 2004, 149:40-49.

132. Carlson NG, Rojas MA, Redd JW, Tang P, Wood B, Hill KE, Rose JW: Cyclooxygenase-2 expression in oligodendrocytes increases sensitivity to excitotoxic death. J Neuroinflammation 2010, 7:25.

133. Gveric D, Kaltschmidt C, Cuzner ML, Newcombe J: Transcription factor NF-KB and inhibitor IKBa are localized in macrophages in active multiplesclerosis lesions. J Neuropathol Exp Neurol 1998, 57:168-178.

134. Bonetti B, Stegagno C, Cannella B, Rizzuto N, Moretto G, Raine CS: Activation of NF-kappaB and c-jun transcription factors in multiple sclerosis lesions. Implications for oligodendrocyte pathology. Am J Pathol 1999, 155:1433-1438.

135. Mattson MP, Camandola S: NF-kappaB in neuronal plasticity and neurodegenerative disorders. J Clin Invest 2001, 107:247-254

136. Link H, Fredrikson S: HLA-DR expression and neopterin levels as activity markers in multiple sclerosis. Riv Neurol 1987, 57:154-158.

137. Khorami H, Neyestani TR, Kadkhodaee M, Lotfi J: Increased urinary neopterin: creatinine ratio as a marker of activation of cell- mediated immunity and oxidative stress in the Iranian patients with multiple sclerosis. Iran J Allergy Asthma Immunol 2003, 2:155-158.

138. Giovannoni G, Lai M, Kidd D, Thorpe JW, Miller DH, Thompson AJ, Keir G, Feldmann M, Thompson EJ: Daily urinary neopterin excretion as an 
immunological marker of disease activity in multiple sclerosis. Brain 1997, 120:1-13.

139. Rejdak K, Leary SM, Petzold A, Thompson AJ, Miller DH, Giovannoni G: Urinary neopterin and nitric oxide metabolites as markers of interferon beta-1a activity in primary progressive multiple sclerosis. Mult Scler 2010, 16:1066-1072.

140. Fredrikson S, Link $H$, Eneroth P: CSF neopterin as marker of disease activity in multiple sclerosis. Acta Neurol Scand 1987, 75:352-355.

141. Buchwald D, Wener MH, Pearlman T, Kith P: Markers of inflammation and immune activation in chronic fatigue and chronic fatigue syndrome. J Rheumatol 1997, 24:372-376.

142. Matsuda J, Gohchi K, Gotch N: Serum concentrations of 2',5'oligoadenylate synthetase, neopterin, and beta-glucan in patients with chronic fatigue syndrome and in patients with major depression. J Neurol Neurosurg Psychiatry 1994, 57:1015-1016.

143. Chao CC, Gallagher M, Phair J, Peterson PK: Serum neopterin and interleukin-6 levels in chronic fatigue syndrome. J Infect Dis 1990, 162:1412-1413.

144. Chao CC, Janoff EN, Hu SX, Thomas K, Gallagher M, Tsang M, Peterson PK: Altered cytokine release in peripheral blood mononuclear cell cultures from patients with the chronic fatigue syndrome. Cytokine 1991, 3:292-298.

145. Fransson ME, Liljenfeldt LS, Fagius J, Totterman TH, Loskog AS: The T-cell pool is anergized in patients with multiple sclerosis in remission. Immunology 2009, 126:92-101.

146. Saresella M, Marventano I, Longhi R, Lissoni F, Trabattoni D, Mendozzi L, Caputo D, Clerici M: CD4 + CD25 + FoxP3 + PD1- regulatory T cells in acute and stable relapsing-remitting multiple sclerosis and their modulation by therapy. FASEB J 2008, 22:3500-3508.

147. Viglietta $V$, Baecher-Allan C, Weiner $\mathrm{HL}$, Hafler DA: Loss of functional suppression by CD4 + CD25+ regulatory T cells in patients with multiple sclerosis. J Exp Med 2004, 199:971-979.

148. Ni L, Ma CJ, Zhang Y, Nandakumar S, Zhang CL, Wu XY, Borthwick T, Hamati A, Chen XY, Kumaraguru U, Moorman JP, Yao ZQ: PD-1 modulates regulatory $\mathrm{T}$ cells and suppresses T-cell responses in HCV-associated lymphoma. Immunol Cell Biol 2011, 89:535-539.

149. Costantino CM, Baecher-Allan C, Hafler DA: Multiple sclerosis and regulatory T cells. J Clin Immunol 2008, 28:697-706.

150. Zozulya AL, Wiendl $H$ : The role of regulatory $T$ cells in multiple sclerosis. Nat Clin Pract Neurol 2008, 4:384-398.

151. Libera DD, Mitri DD, Bergami A, Centonze D, Gasperini C, Grasso MG, Galgani S, Martinelli V, Comi G, Avolio C, Martino G, Borsellino G, Sallusto F, Battistini L, Furlan R: T regulatory cells are markers of disease activity in multiple sclerosis patients. PLOS ONE 2011, 6:e21386.

152. D'Souza M, Fontenot AP, Mack DG, Lozupone C, Dillon S, Meditz A, Wilson CC, Connick E, Palmer BE: Programmed death 1 expression on HIVspecific CD4+ T cells is driven by viral replication and associated with $T$ cell dysfunction. J Immunol 2007, 179:1979-1987.

153. Song SJ, Feng X, Guo JJ, lu YN, Lun WH, Wei HS, Liu SA: Relationship of CD4+ CD25hi regulatory T (Treg) cells to disease progression in HIVinfected patients. Zhonghua Shi Yan He Lin Chuang Bing Du Xue Za Zhi 2009, 23:361-363.

154. Hofstetter HH, Gold R, Hartung HP: Th17 cells in MS and experimental autoimmune encephalomyelitis. Int MS J 2009, 16:12-18.

155. Peelen E, Damoiseaux J, Smolders J, Knippenberg S, Menheere P, Tervaert JW, Hupperts R, Thewissen M: Th17 expansion in MS patients is counterbalanced by an expanded CD39+ regulatory $T$ cell population during remission but not during relapse. J Neuroimmunol 2011, 240-241:97-103.

156. Weissert R: Differential response to treatment of relapsing-remitting multiple sclerosis with IFN- $\beta$ : is there a dichotomy into T-helper-1 and -17 driven disease? Future Neurol 2010, 5:481-484.

157. Edwards LJ, Robins RA, Constantinescu CS: Th17/Th1 phenotype in demyelinating disease. Cytokine 2010, 50:19-23.

158. Kostic M: Role of Th1 and Th17 immune responces in pathogenesis of multiple sclerosis. Acta Medica Medianae 2010, 49:61-69.

159. Ziegler SF, Buckner JH: FOXP3 and the regulation of Treg/Th17 differentiation. Microbes Infect 2009, 11:594-598.

160. Zhou L, Lopes JE, Chong MM, Ivanov II, Min R, Victora GD, Shen Y, Du J, Rubtsov YP, Rudensky AY, Ziegler SF, Littman DR: TGF-beta-induced Foxp3 inhibits $\mathrm{T}(\mathrm{H}) 17$ cell differentiation by antagonizing RORgammat function. Nature 2008, 453:236-240.
161. Liu DH, Liu ZD, Li YZ, Zhang HY, Hu CJ, Zhang YB, Whang DX: Expression of lymphocyte subsets and CD25 + regulative T Cells in peripheral blood of patients with chronic fatigue syndrome. Labeled Immunoassays and Clinical Medicine. Abstract 2011, 2011-02. http://en.cnki.com.cn/ Article_en/CJFDTOTAL-BJMY201102012.htm.

162. Gallo P, Piccinno MG, Pagni S, Argentiero V, Giometto B, Bozza F, Tavolato B: Immune activation in multiple sclerosis: study of IL-2, sIL-2R, and gamma-IFN levels in serum and cerebrospinal fluid. J Neurol Sci 1989, 92:9-15.

163. Gallo P, Piccinno MG, Tavolato B, Siden A: A longitudinal study on IL-2, sIL-2R, IL-4 and IFN-gamma in multiple sclerosis CSF and serum. J Neurol Sci 1991, 101:227-232

164. Gallo P, Pagni S, Piccinno MG, Giometto B, Argentiero V, Chiusole M, Bozza $F$, Tavolato B: On the role of interleukin-2 (IL-2) in multiple sclerosis (MS). IL-2-mediated endothelial cell activation. Ital J Neurol Sci 1992, 13:65-68.

165. Sharief MK, Hentges R, Ciardi M, Thompson EJ: In vivo relationship of interleukin-2 and soluble IL-2 receptor to blood-brain barrier impairment in patients with active multiple sclerosis. J Neurol 1993, 240:46-50.

166. Cheney PR, Dorman SE, Bell DS: Interleukin-2 and the chronic fatigue syndrome. Ann Intern Med 1989, 110:321.

167. Lombardi V, Hagen KS, Hunter KW, Diamond JW, Smith-Gagen J, Yang W, Mikovits JA: Xenotropic murine leukemia virus-related virus-associated chronic fatigue syndrome reveals a distinct inflammatory signature. In Vivo 2011, 25:307-314.

168. Popmihajlov Z, Smith KA: Negative feedback regulation of T cells via interleukin-2 and FOXP3 reciprocity. PLOS ONE 2008, 3:e1581.

169. Klimas N, Koneru AO: Chronic fatigue syndrome: inflammation, immune function, and neuroendocrine interactions. Curr Rheumatol Rep 2007, 9:482-487.

170. Capelli E, Zola R, Lorusso L, Venturini L, Sardi F, Ricevuti G: Chronic fatigue syndrome/myalgic encephalomyelitis: an update. Int J Immunopathol Pharmacol 2010, 23:981-989.

171. Jones JF, Straus SE: Chronic Epstein-Barr virus infection. Annu Rev Med 1987, 38:195-209.

172. Borysiewicz LK, Haworth SJ, Cohen J, Mundin J, Rickinson A, Sissons JG: Epstein-Barr virus - specific immune defects in patients with persistent symptoms following infectious mononucleosis. Q J Med 1986, 58:111-121

173. Klimas N, Salvato F, Morgan R, Fletcher MA: Immunologic abnormalities in chronic fatigue syndrome. J Clin Microbiol 1990, 28:1403-1410.

174. Behan PO, Behan WHM, Bell EJ: The postviral fatigue syndrome - an analysis of the findings in 50 cases. J Infect 1985, 10:211-222.

175. Tobi M, Morag A, Ravid Z, Chowers I, Feldman-Weiss V, Michaeli Y, Ben-Chetrit E, Shalit M, Knobler H: Prolonged atypical illness associated with serological evidence of persistent Epstein-Barr infection. Lancet 1982, 1:61-64.

176. Morimoto C, Torimoto Y, Levinson G, Rudd CE, Schrieber M, Dang NH, Letvin NL, Schlossman SF: 1 F7, a novel cell surface molecule involved in helper function of CD4 cells. J Immunol 1989, 143:3430-3439.

177. Nakao H, Eguchi K, Kawakami A, Migita K, Otsubo T, Ueki Y, Shimomura C, Tezuka H, Matsunaga M, Maeda K, et al: Increment of Tal positive cells in peripheral blood of patients with rheumatoid arthritis. J Rheumatol 1989 16:904-910.

178. Eguchi K, Ueki Y, Shimomura C, Otsubo T, Nakao H, Migita K, Kawakami A, Matsunaga $\mathrm{M}$, Tezuka $\mathrm{H}$, Ishikawa $\mathrm{N}$ : Increment in the Tal + in the peripheral blood and thyroid tissue of patients with Graves' disease. J Immunol 1989, 142:4233-4240.

179. Preller V, Gerber A, Togni M, Wrenger S, Schraven B, Rocken C, Marguet D, Ansorge S, Brocke S, Reinhold D: CD26/DP IV in T cell activation and autoimmunity. Adv Exp Med Biol 2006, 575:187-193.

180. Ishii T, Ohnuma K, Murakami A, Takasawa N, Kobayashi S, Dang NH, Schlossman SF, Morimoto C: CD26-mediated signaling for T cell activation occurs in lipid rafts through its association with CD45RO. Proc Natl Acad Sci U S A 2001, 98:12138-12143.

181. Pacheco R, Lluis C, Franco R: Role of CD26-adenosine deaminase interaction in T cell-mediated immunity. Inmunologia 2005, 24:235-245.

182. Bengsch B, Seigel B, Flecken T, Wolanksi J, Blum HE, Thimme R: Human Th17 cells express high levels of enzymatically active dipeptidylpeptidase IV (CD26). J Immunol 2012, 188:5438-5447.

183. Krakauer M, Sorenson PS, Sellebjerg F: CD4(+) memory T cells with high CD26 surface expression are enriched for Th1 markers and correlate 
with clinical severity of multiple sclerosis. J Neuroimmunol 2006, 181:157-164.

184. Constantinescu CS, Kamoun M, Dotti M, Farber RE, Galetta SL, Rostami A: A longitudinal study of the T cell activation marker CD26 in chronic progressive multiple sclerosis. J Neurol Sci 1995, 130:178-182.

185. Sellebjerg F, Ross C, Koch-Henriksen N, Sorensen PS, Frederiksen JL, Bendtzen K, Sorensen TL: CD26 + CD4 + T cell counts and attack risk in interferon-treated multiple sclerosis. Mult Scler 2005, 11:641-645.

186. Fletcher MA, Zeng XR, Maher K, Levis S, Hurwitz B, Antoni M, Broderick G, Klimas NG: Biomarkers in chronic fatigue syndrome: evaluation of natural killer cell function and dipeptidyl peptidase IV/CD26. PLOS ONE 2010, 5:e10817.

187. Martin P, Sanchez-Madrid F: CD69: an unexpected regulator of TH17 cell-driven inflammatory responses. Sci Signal 2011, 4:pe14.

188. Perrella O, Carrieri PB, De Mercato R, Buscaino GA: Markers of activated T Lymphocytes and T cell receptor Gamma/Delta + in patients with multiple sclerosis. Eur Neurol 1993, 33:152-155.

189. Huang YM, Hussien Y, Jin YP, Soderstrom M, Link H: Multiple sclerosis: deficient in vitro responses of blood mononuclear cells to IFN-beta. Acta Neurol Scand 2001, 104:249-256.

190. Mihaylova I, DeRuyter M, Rummens JL, Bosmans E, Maes M: Decreased expression of CD69 in chronic fatigue syndrome in relation to inflammatory markers: evidence for a severe disorder in the early activation of T lymphocytes and natural killer cells. Neuro Endocrinol Lett 2008, 28:477-483.

191. Zhang C, Zhang J, Tian Z: The regulatory effect of natural killer Cells: do "NK-reg cells" exist? Cell Mol Immunol 2006, 3:241-254.

192. Benczur M, Petrynyl GG, Palffy G, Varga M, Talas M, Kotsy B, Foldes I, Hollan SR: Dysfunction of natural killer cells in multiple sclerosis: a possible pathogenetic factor. Clin Exp Immunol 1980, 39:657-662.

193. Jiang W, Chai NR, Maric D, Bielekova B: Unexpected role for granzyme $K$ in CD56 bright NK cell-mediated immunoregulation of multiple sclerosis. J Immunol 2011, 187:781-790.

194. Kastrukoff LF, Lau A, Wee R, Zecchini D, White R, Paty DW: Clinical relapses of multiple sclerosis are associated with 'novel' valleys in natural killer cell functional activity. J Neuroimmunol 2003, 145:103-114.

195. Takahashi K, Aranami T, Endoh M, Miyake S, Yamamura T: The regulatory role of natural killer cells in multiple sclerosis. Brain 2004, 127:1917-1927.

196. Bielekova B, Catalfamo M, Reichert-Scrivner S, Packer A, Cerna M, Waldmann TA, McFarland H, Henkart PA, Martin R: Regulatory CD56 bright natural killer cells mediate immunomodulatory effects of IL-2Ralpha-targeted therapy (daclizumab) in multiple sclerosis. Proc Natl Acad Sci U S A 2006, 103:5941-5946.

197. Caligiuri M, Murray C, Buchwald D, Levine H, Cheney P, Peterson D, Komaroff $A L$, Ritz J: Phenotypic and functional deficiency of natural killer cells in patients with chronic fatigue syndrome. J Immunol 1987, 139:3306-3313.

198. Whiteside TL, Friberg D: Natural killer cells and natural killer cell activity in chronic fatigue syndrome. Am J Med 1998, 105:27S-34S

199. Genc K, Dona DL, Reder AT: Increased CD80(+) B cells in active multiple sclerosis and reversal by interferon beta-1b therapy. J Clin Invest 1997, 99:2664-2671

200. Nijs J, McGregor NR, De Becker P, Verhas M, Englebienne P, De Meirleir K: Monitoring a hypothetical channelopathy in chronic fatigue syndrome: preliminary observations. JCFS 2003, 11:117-133.

201. Nijs J, Coomans D, Nicolson GL, De Becker P, Christian D, De Meirleir K: Immunophenotyping predictive of mycoplasma infection in patients with chronic fatigue syndrome. JCFS 2003, 11:51-69.

202. Tirelli U, Marotta G, Improta S, Pinto A: Immunological abnormalities in patients with chronic fatigue syndrome. Scand J Immunol 1994, 40:601-608

203. Anderton SM, Fillatreau S: Activated B cells in autoimmune diseases: the case for a regulatory role. Nat Clin Pract Rheumatol 2008, 4:657-666.

204. Barned S, Goodman AD, Mattson DH: Frequency of anti-nuclear antibodies in multiple sclerosis. Neurology 1995, 45:384-385

205. Fukazawa T, Moriwaka F, Mukai M, Hamada T, Koike T, Tashiro K: Anticardiolipin antibodies in Japanese patients with multiple sclerosis. Acta Neurol Scand 1993, 88:184-189.

206. IJdo JW, Conti-Kelly AM, Greco P, Abedi M, Amos M, Provenzale JM, Greco TP: Anti-phospholipid antibodies in patients with multiple sclerosis and MS-like illnesses: MS or APS? Lupus 1999, 8:109-115.
207. Vyshkina T, Kalman B: Autoantibodies and neurodegeneration in multiple sclerosis. Lab Invest 2008, 88:796-807.

208. Nordal GJ, Vandvik B: Evidence of local synthesis of smooth-muscle antibodies in the central nervous system in isolated cases of multiple sclerosis and chronic lymphocytic meningoencephalitis. Scand J Immunol 1977, 6:327-334

209. Arnon R, Crisp E, Kelley R, Ellison GW, Myers LW, Tourtellotte WW: Anti-ganglioside antibodies in multiple sclerosis. J Neurol Sci 1980, 46:179-186.

210. Schott K, Schaefer JE, Richartz E, Batra A, Eusterschulte B, Klein R, Berg PA, Bartels M, Mann K, Buchkremer G: Autoantibodies to serotonin in serum of patients with psychiatric disorders. Psychiatr Res 2003, 121:51-57.

211. Hokama Y, Camproa CE, Hara C, Higa N, Siu N, Lau R, Kuribayashi T, Yabusaki K: Acute phase phospholipids related to the cardiolipin of mitochondria in the sera of patients with chronic fatigue syndrome (CFS), chronic Ciguatera fish poisoning (CCFP), and other diseases attributed to chemicals, Gulf War, and marine toxins. J Clin Lab Anal 2008, 22:99-105.

212. Hokama Y, Camproa CE, Hara C, Kuribayashi T, Le Huynh D, Yabusaki K: Anticardiolipin antibodies in the sera of patients with diagnosed chronic fatigue syndrome. J Clin Lab Anal 2009, 23:210-212.

213. Konstantinov K, von Mikecz A, Buckwalk D, Jones J, Gerace L, Tan EM: Autoantibodies to nuclear envelope antigens in chronic fatigue syndrome. J Clin Invest 1996, 98:1888-1896.

214. Buchwald MD, Wener MH, Komaroff AL: Antineuronal antibody levels in chronic fatigue syndrome patients with neurologic abnormalities. Arthritis Rheum 1991, 34:1485-1486

215. Nishikai M: Antinuclear antibodies in patients with chronic fatigue syndrome. Nippon Rinsho 2007, 65:1067-1070.

216. Bassi N, Amital D, Amital H, Doria A, Shoenfeld Y: Chronic fatigue syndrome: characteristics̃and possible causes for its pathogenesis. Isr Med Assoc J 2008, 10:79-82.

217. Klein R, Berg PA: High incidence of antibodies to 5-hydroxytryptamine, gangliosides and phospholipids in patients with chronic fatigue and fibromyalgia syndrome and their relatives: evidence for a clinical entity of both disorders. Eur J Med Res 1995, 1:21-26.

218. Tanaka S, Kuratsune H, Hidaka Y, Hakariya Y, Tatsumi KI, Takano T, Kanakura $Y$, Amino N: Autoantibodies against muscarinic cholinergic receptor in chronic fatigue syndrome. Int J Mol Med 2003, 12:225-230.

219. Geffard M, Bodet D, Martinet Y, Dabadie MP: Detection of the specific IgM and IgA circulating in sera of multiple sclerosis patients: interest and perspectives. Immunoanalyse Biologie Specialisee 2002, 17:302-310.

220. Daverat P, Geffard M, Orgogozo JM: Identification and characterization of anti-conjugated azelaic acid antibodies in multiple sclerosis. J Neuroimmunol 1989, 22:129-314.

221. Maneta-Peyret L, Daverat P, Geffard M, Cassagne C, Orgogozo JM: Natural seric anti-fatty acid antibodies in multiple sclerosis. Neurosci Lett 1987, 80:235-239.

222. Boullerne A, Petry KG, Geffard M: Circulating antibodies directed against conjugated fatty acids in sera of patients with multiple sclerosis. J Neuroimmunol 1996, 65:75-81.

223. Naidoo R, Knapp ML: Studies of lipid peroxidation products in cerebrospinal fluid and serum in multiple sclerosis and other conditions. Clin Chem 1992, 38:2449-2454.

224. Maes M, Mihaylova I, Leunis JC: Increased serum IgM antibodies directed against phosphatidyl inositol (Pi) in chronic fatigue syndrome (CFS) and major depression: evidence that an IgM-mediated immune response against $\mathrm{Pi}$ is one factor underpinning the comorbidity between both CFS and depression. Neuro Endocrinol Lett 2007, 28:861-867.

225. McFarland HF: The B cell-old player, new position on the team. $N$ Engl J Med 2008, 2008:664-665

226. Hauser SL, Waubant E, Arnold DL, Vollmer T, Antel J, Fox RJ, Bar-Or A Panzara M, Sarkar N, Agarwal S, Langer-Gould A, Smith CH, HERMES Trial Group: B-cell depletion with rituximab in relapsing-remitting multiple sclerosis. New Engl J Med 2008, 358:676-688.

227. Monson NL, Cravens PD, Frohman EM, Hawker K, Racke MK: Effect of rituximab on the peripheral blood and cerebrospinal fluid $B$ cells in patients with primary progressive multiple sclerosis. Arch Neurol 2005, 62:258-264.

228. Maurer MA, Rakocevic G, Leung CS, Quast I, Lukacisin M, Goebels N, Munz C, Wardemann H, Dalakas M, Lnemann JD: Rituximab induces sustained 
reduction of pathogenic $B$ cells in patients with peripheral nervous system autoimmunity. J Clin Invest 2012, 122:1393-1402.

229. Cross AH, Stark JL, Lauber J, Ramsbottom MJ, Lyons JA: Rituximab reduces $B$ cells and T cells in cerebrospinal fluid of multiple sclerosis patients. J Neuroimmunol 2006, 180:63-70.

230. Bar-Or A, Fawaz L, Fan B, Darlington PJ, Rieger A, Ghorayeb C, Calabresi PA Waubant E, Hauser SL, Zhang J, Smith CH: Abnormal B-cell cytokine responses a trigger of T-cell-mediated disease in MS? Ann Neurol 2010, 67:452-461.

231. Reichardt P, Dornbach B, Rong S, Beissert S, Gueler F, Loser K, Gunzer M: Naive B cells generate regulatory $T$ cells in the presence of a mature immunologic synapse. Blood 2007, 110:1519-1529.

232. Petereit HF, Moeller-Hartmann W, Reske D, Rubbert A: Rituximab in a patient with multiple sclerosis-effect on B cells, plasma cells and intrathecal lgG synthesis. Acta Neurol Scand 2008, 117:399-403.

233. Fluge O, Bruland O, Risa K, Storstein A, Kristoffersen EK, Sapkota D, Næss $H$, Dahl O, Nyland $H$, Mella O: Benefit from B-lymphocyte depletion using the anti-CD20 antibody rituximab in chronic fatigue syndrome: a double-blind and placebo-controlled study. PLOS ONE 2011, 6:e26358.

234. Emery P, Fleischmann R, Filipowicz-Sosnowska A, Schechtman J, Szczepansk L, Kavanaugh A, Racewicz AJ, van Vollenhoven RF, Li NF, Agarwal S, Hessey EW, Shaw TM, DANCER Study Group: The efficacy and safety of rituximab in patients with active rheumatoid arthritis despite methotrexate treatment: results of a phase IIB randomized, double-blind, placebocontrolled, dose-ranging trial. Arthritis Rheum 2006, 54:1390-1400.

235. Eisenberg R: Update on rituximab. Ann Rheum Dis 2005, 64:iv55-iv57.

236. Gurcan HM, Keskin DB, Stern JN, Nitzberg MA, Shekhani H, Ahmed AR: A review of the current use of rituximab in autoimmune diseases. Int Immunopharmacol 2009, 9:10-25.

237. Edwards JC, Szczepanski L, Szechinski J, Filipowicz-Sosnowska A, Emery P, Close DR, Stevens RM, Shaw T: Efficacy of B-cell-targeted therapy with rituximab in patients with rheumatoid arthritis. N Engl J Med 2004, 350:2572-2581.

238. Cohen SB, Emery P, Greenwald MW, Dougados M, Furie RA, Genovese MC, Keystone EC, Loveless JE, Burmester GR, Cravets MW, Hessey EW, Shaw T, Totoritis MC, REFLEX Trial Group: Rituximab for rheumatoid arthritis refractory to anti-tumor necrosis factor therapy: results of a multicenter, randomized, double-blind, placebo-controlled, phase III trial evaluating primary efficacy and safety at twenty-four weeks. Arthritis Rheum 2006, 54:2793-2806

239. Tokunaga M, Saito K, Kawabata D, Imura Y, Fujii T, Nakayamada S, Tsujimura S, Nawata M, Iwata S, Azuma T, Mimori T, Tanaka Y: Efficacy of rituximab (anti-CD20) for refractory systemic lupus erythematosus involving the central nervous system. Ann Rheum Dis 2007, 66:470-475.

240. Devauchelle-Pensec V, Pennec Y, Morvan J, Pers JO, Daridon C, JousseJoulin S, Roudaut A, Jamin C, Renaudineau Y, Roue IQ, Cochener B, Youinou $P$, Saraux A: Improvement of Sjogren's syndrome after two infusions of rituximab (anti-CD20). Arthritis Rheum 2007, 57:310317.

241. Ireland $\mathrm{S}$, Monson $\mathrm{N}$ : Potential impact of $\mathrm{B}$ cells on $\mathrm{T}$ cell function in multiple sclerosis. Mult Scler Int 2011, 2011:423971.

242. van de Veerdonk FL, Lauwerys B, Marijnissen RJ, Timmermans K, Di Padova F, Koenders MI, Gutierrez-Roelens I, Durez P, Netea MG, van der Meer JW van den Berg WB, Joosten LA: The anti-CD20 antibody rituximab reduces the Th17 cell response. Arthritis Rheum 2011, 63:1507-1516.

243. Lederer JA, Liou JS, Kim S, Rice N, Lichtman AH: Regulation of NF-kappa B activation in T helper 1 and T helper 2 cells. J Immunol 1996, 156:56-63.

244. Jazirehi AR, Huerta-Yepez S, Cheng G, Bonavida B: Rituximab (chimericantiCD20 monoclonal antibody) inhibits the constitutive nuclear factor\{kappa\}B signaling pathway in non-Hodgkin's lymphoma B-cell lines: role in sensitization to chemotherapeutic drug-induced apoptosis. Cancer Res 2005, 65:264-276.

245. Bonavida B: Rituximab-induced inhibition of antiapoptotic cell survival pathways: implications in chemo/immunoresistance, rituximab unresponsiveness, prognostic and novel therapeutic interventions. Oncogene 2007, 26:3629-3636.

246. Vigna-Perez M, Hernandez-Castro B, Paredes-Saharopulos O, Portales-Perez D, Baranda L, Abud-Mendoza C, Gonzalez-Amaro R: Clinical and immunological effects of rituximab in patients with lupus nephritis refractory to conventional therapy: a pilot study. Arthritis Res Ther 2006, 8:R83.
247. Vigna-Perez M, Abud-Mendoza C, Cuevas-Orta E, Baranda L, ParedesSaharopulos O, Moreno R, Gonzalez-Amaro R: In vivo effect of rituximab on regulatory $T$ cells and apoptosis in patients with rheumatoid arthritis. Immunologia 2006, 25:167-172.

248. Tavazzi B, Batocchi AP, Amorini AM, Nociti V, D’Urso S, Longo S, Gullotta S, Picardi M, Lazzarino G: Serum metabolic profile in multiple sclerosis patients. Mult Scler Int 2011, 2011:167156.

249. Amorini AM, Petzold A, Tavazzi B, Eikelenboom J, Keir G, Belli A, Giovannoni G, Di Pietro V, Polman C, D'Urso S, Vagnozzi R, Uitdehaag B, Lazzarino G: Increase of uric acid and purine compounds in biological fluids of multiple sclerosis patients. Clin Biochem 2009, 42:1001-1006.

250. Amorini M, Lazzarino G, Galvano F, Fazzina G, Tavazzi B, Galvano G: Cyanidin-3-O-beta-glucopyranoside protects myocardium and erythrocytes from oxygen radical-mediated damages. Free Radic Res 2003, $37: 453-460$

251. Signoretti S, Di Pietro V, Vagnozzi R, Lazzarino G, Amorini AM, Belli A, D'Urso S, Tavazzi B: Transient alterations of creatine, creatine phosphate, $\mathrm{N}$-acetylaspartate and high-energy phosphates after mild traumatic brain injury in the rat. Mol Cell Biochem 2010, 333:269-277.

252. Lazzarino G, Amorini AM, Eikelenboom MJ, Killestein J, Belli A, Di Pietro V, Tavazzi B, Barkhof F, Polman CH, Uitdehaag BM, Petzold A: Cerebrospinal fluid ATP metabolites in multiple sclerosis. Mult Scler 2010, 16:549-554

253. Lassman $H$, van Horssen J: The molecular basis of neurodegeneration in multiple sclerosis. FEBS Lett 2011, 585:3715-3723.

254. Lu F, Selak M, O'Connor J, Croul S, Lorenzana C, Butunoi C, Kalman B: Oxidative damage to mitochondrial DNA and activity of mitochondrial enzymes in chronic active lesions of multiple sclerosis. J Neurol Sci 2000, 177:95-103

255. Mahad D, Ziabreva I, Lassmann H, Turnbull D: Mitochondrial defects in acute multiple sclerosis lesions. Brain 2008, 131:1722-1735.

256. Mahad D, Ziabreva I, Campbell G, Lax N, White K, Hanson PS, Lassmann H, Turnbull DM: Mitochondrial changes within axons in multiple sclerosis. Brain 2009, 132:1161-1174.

257. Campbell GR, Ziabreva I, Reeve AK, Krishnan KJ, Reynolds R, Howell O, Lassmann H, Turnbull DM, Mahad DJ: Mitochondrial DNA deletions and neurodegeneration in multiple sclerosis. Ann Neurol 2011, 69:481-492.

258. Higgins GC, Beart PM, Shin YS, Chen MJ, Cheung NS, Nagley P: Oxidative stress: emerging mitochondrial and cellular themes and variations in neuronal injury. J Alzheimers Dis 2010, 20:\$453-\$473.

259. Mao P, Reddy H: Is multiple sclerosis a mitochondrial disease? Biochim Biophys Acta 2010, 1802:66-79.

260. van Horssen J, Witte ME, Schreibelt G, de Vries HE: Radical changes in multiple sclerosis pathogenesis. Biochem Biophys Acta 2011, 1812:141-150.

261. Behan WM, More IA, Behan PO: Mitochondrial abnormalities in the postviral fatigue syndrome. Acta Neuropathol 1991, 83:61-65.

262. Plioplys AV, Plioplys S: Electron-microscopic investigation of muscle mitochondria in chronic fatigue syndrome. Neuropsychobiology 1995 32:175-181.

263. Lane RJ, Barrett MC, Taylor DJ, Kemp GJ, Lodi R: Heterogeneity in chronic fatigue syndrome: evidence from magnetic resonance spectroscopy of muscle. Neuromuscul Disord 1998, 8:204-209.

264. Myhill S, Booth NE, McLaren-Howard J: Chronic fatigue syndrome and mitochondrial dysfunction. Int J Clin Exp Med 2009, 2:1-16.

265. Vermeulen RCW, Kurt RM, Visser FC, Sluiter W, Scholte HR: Patients with chronic fatigue syndrome performed worse than controls in a controlled repeated exercise study despite a normal oxidative phosphorylation capacity. J Transl Med 2010, 8:93.

266. Arnold DL, Bore PJ, Radda GK, Styles P, Taylor DJ: Excessive intracellular acidosis of skeletal muscle on exercise in a patient with a post-viral exhaustion/fatigue syndrome. Lancet 1984, 1:1367-1369.

267. Lane RJM, Barrett MC, Woodrow D, Moss J, Fletcher R, Archard LC: Muscle fibre characteristics and lactate responses to exercise in chronic fatigue syndrome. J Neurol Neurosurg Psychiatry 1998, 64:362-367.

268. Allen DG, Lamb GD, Westerbland H: Skeletal muscle fatigue: cellular mechanisms. Physiol Rev 2008, 88:287-332.

269. Wong R, Lopaschuk G, Zhu G, Walker D, Catellier D, Burton D, Teo K, CollinsNakai R, Montague T: Skeletal muscle metabolism in the chronic fatigue syndrome. In vivo assessment by 31P nuclear magnetic resonance spectroscopy. Chest 1992, 102:1716-1722. 
270. Mathew SJ, Mao X, Keegan KA, Levine SM, Smith EL, Heier LA, Otcheretko V, Coplan JD, Shungu DC: Ventricular cerebrospinal fluid lactate is increased in chronic fatigue syndrome compared with generalized anxiety disorder: an in vivo 3.0 T (1)H MRS imaging study. NMR Biomed 2009, 22:251-258

271. Murrough JW, Mao X, Collins KA, Kelly C, Andrade G, Nestadt P, Levine SM, Mathew SJ, Shungu DC: Increased ventricular lactate in chronic fatigue syndrome measured by $1 \mathrm{H}$ MRS imaging at $3.0 \mathrm{~T}$. Il: comparison with major depressive disorder. NMR Biomed 2010, 23:643-650.

272. Pozzilli C, Passafiume D, Bernardi S, Incoccia C, Bastianello S, Bozzao L, Lenzi GL, Fleschi C: SPECT, MRI and cognitive functions in multiple sclerosis. J Neurol Neurosurg Psychiatry 1991, 54:110-115.

273. Adhya S, Johnson G, Herbert J, Jaggi H, Babb JS, Grossman Rl, Inglese M: Pattern of hemodynamic impairment in multiple sclerosis: dynamic susceptibility contrast perfusion MR imaging at 3.0 T. Neuroimage 2006, 33:1029-1035

274. Brooks DJ, Leenders KL, Head G, Marshall J, Legg NJ, Jones T: Studies on regional cerebral oxygen utilisation and cognitive function in multiple sclerosis. J Neurol Neurosurg Psychiatry 1984, 47:1182-1191.

275. Raschid W, Parkes LM, Ingle GT, Chard DT, Toosy AT, Altmann DR, Symms MR, Tofts PS, Thompson AJ, Miller DH: Abnormalities of cerebral perfusion in multiple sclerosis. J Neurol Neurosurg Psychiatry 2004, 75:1288-1293.

276. Costa DC, Tannock C, Brostoff J: Brainstem perfusion is impaired in chronic fatigue syndrome. QJM 1995, 88:767-773.

277. Fischler B, D'Haenen $H$, Cluydts R, Michiels V, Demets K, Bossuyt A, Kaufman L, De Meirleir K: Comparison of 99m Tc HMPAO SPECT scan between chronic fatigue syndrome, major depression and healthy controls: an exploratory study of clinical correlates of regional cerebral blood flow. Neuropsychobiol 1996, 34:175-183.

278. Schwartz RB, Garada BM, Komaroff AL, Tice HM, Gleit M, Jolesz FA, Holman BL: Detection of intracranial abnormalities in patients with chronic fatigue syndrome: comparison of MR imaging and SPECT. AJR Am J Roentgenol 1994, 162:935-941.

279. Ichise M, Salit IE, Abbey SE, Chung DG, Gray B, Kirsh JC, Freedman M: Assessment of regional cerebral perfusion by 99Tcm-HMPAO SPECT in chronic fatigue syndrome. Nucl Med Commun 1992, 13:767-772.

280. Tirelli U, Chierichetti F, Tavio M, Simonelli C, Bianchin G, Zanco P, Ferlin G: Brain positron emission tomography (PET) in chronic fatigue syndrome: preliminary data. Am J Med 1998, 105:54S-58S.

281. I'ves AG, Prakhova LN, Kataeva GV, Rudas MS, Tomolian NA, Skoromets AA, Stoliarov ID: Changes of cerebral glucose metabolism in patients with multiple sclerosis and their role in formation of the clinical picture and progression of the disease. Zh Nevrol Psikhiatr Im SS Korsakova 2003, 2:53-60.

282. Roelcke U, Kappos L, Lechner-Scott J, Brunnschweiler H, Huber S, Ammann W, Plohmann A, Dellas S, Maguire RP, Missimer J, Radu EW, Steck A, Leenders KL: Reduced glucose metabolism in the frontal cortex and basal ganglia of multiple sclerosis patients with fatigue $\mathrm{A} 18 \mathrm{~F}$ fluorodeoxyglucose positron emission tomography study. Neurology 1997, 48:1566-1571.

283. Paulasu E, Perani D, Fazio F, Comi G, Pozzilli C, Martinelli V, Filippi M, Bettinardi V, Sirabian G, Passafiume D, Anzini A, Lenzi GL, Canal N, Fieschi C: Functional basis of memory impairment in multiple sclerosis: a [18F]FDG PET study. Neuroimage 1996, 4:87-96.

284. Siessmeier T, Nix W, Hardt J, Schreckenberger M, Egle U, Bartenstein P: Observer independent analysis of cerebral glucose metabolism in patients with chronic fatigue syndrome. J Neurol Neurosurg Psychiatry 2003, 74:922-928.

285. Neema M, Stankiewicz J, Arora A, Guss ZD, Bakshi R: MRI in multiple sclerosis: what's inside the toolbox? Neurotherapeutics 2007, 4:602-617.

286. Kohler SJ, Yen Y, Wolber J, Chen AP, Albers MJ, Bok R, Zhang V, Tropp J, Nelson S, Vigneron DB, Kurhanewicz J, Hurd RE: In vivo 13 carbon metabolic imaging at 3T with hyperpolarized 13C-1-pyruvate. Magn Reson Med 2007, 58:65-69.

287. Dousset V, Brochet B, Deloire MS, Lagoarde L, Barroso B, Caille JM, Petry KG: MR imaging of relapsing multiple sclerosis patients using ultra-small -particle iron oxide and compared with gadolinium. Am J Neuroradiol 2006, 27:1000-1005

288. Chen JW, Querol Sans M, Bogdanov A Jr, Weissleder R: Imaging of myeloperoxidase in mice by using novel amplifiable paramagnetic substrates. Radiology 2006, 240:473-481.
289. Bakshi R, Dmochowski J, Shaikh ZA, Jacobs L: Gray matter T2 hypointensity is related to plaques and atrophy in the brains of multiple sclerosis patients. J Neurol Sci 2001, 185:19-26

290. Laule C, Vavasour IM, Kolind SH, Traboulsee AL, Moore GR, Li DK, Mackay AL: Long T2 water in multiple sclerosis: what else can we learn from multiecho T2 relaxation? J Neurol 2007, 254:1579-1587.

291. Bo L, Geurts JJ, Mork SJ, van der Valk P: Grey matter pathology in multiplesclerosis. Acta Neurol Scand Supp/ 2006, 183:48-50.

292. Miller DH, Soon D, Fernando KT, MacManus DG, Barker GJ, Yousry TA, Fisher E, O'Connor PW, Phillips JT, Polman CH, Kappos L, Hutchinson M, Havrdova E, Lublin FD, Giovannoni G, Wajgt A, Rudick R, Lynn F, Panzara MA, Sandrock AW, AFFIRM Investigators: MRI outcomes in a placebo-controlled trial of natalizumab in relapsing MS. Neurology 2007, 68:1390-1401.

293. Horakova D, Kalincik T, Dusankova JB, Dolezal O: Clinical correlates of grey matter pathology in multiple sclerosis. BMC Neurol 2012, $12: 10$

294. Prinster A, Quarantelli M, Orefice G, Lanzillo R, Brunetti A, Mollica C, Salvatore E, Morra VB, Coppola G, Vacca G, Alfano B, Salvatore M: Grey matter loss in relapsing-remitting multiple sclerosis: a voxel-based morphometry study. Neuroimage 2006, 29:859-867.

295. Morgen K, Sammer G, Courtney SM, Wolters T, Melchior H, Blecker CR, Oschmann P, Kaps M, Vaitl D: Evidence for a direct association between cortical atrophy and cognitive impairment in relapsing-remitting MS. Neuroimage 2005, 30:891-898.

296. Okada T, Tanak M, Kuratsune H, Watanabe Y, Sadato N: Mechanisms underlying fatigue: a voxel-based morphometric study of chronic fatigue syndrome. BMC Neurol 2004, 4:14.

297. Barnden LR, Crouch B, Kwiatek R, Burnet R, Mernone A, Chryssidis S, Scroop $G$, Del Fante P: A brain MRI study of chronic fatigue syndrome: evidence of brainstem dysfunction and altered homeostasis. NMR Biomed 2011, 24:1302-1312.

298. Puri BK, Jakeman PM, Agour M, Gunatilake KD, Fernando KA, Gurusinghe Al, Treasaden $I H$, Waldman AD, Gishen P: Regional grey and white matter volumetric changes in myalgic encephalomyelitis (chronic fatigue syndrome): a voxel-based morphometry 3-T MRI study. Br J Radiol 2011, 85:e270-e273

299. Natelson $\mathrm{BH}$, Cohen JM, Brassloff I, Lee HJ: A controlled study of brain magnetic resonance imaging in patients with the chronic fatigue syndrome. J Neurol Sci 1993, 120:213-217.

300. Lange G, DeLuca J, Maldjian JA, Lee H, Tiersky LA, Natelson BH: Brain MRI abnormalities exist in a subset of patients with chronic fatigue syndrome. J Neurol Sci 2005, 171:3-7.

301. Matthews PM, Francis G, Antel J, Arnold DL: Proton magnetic resonance spectroscopy for metabolic characterization of plaques in multiple sclerosis. Neurology 1991, 41:1251-1256.

302. Butteriss DJA, Ismail A, Ellison DW, Birchall D: Use of serial proton magnetic resonance spectroscopy to differentiate low grade glioma from tumefactive plaque in a patient with multiple sclerosis. BJR 2003, 76:662-665

303. Hattingen E, Magerkurth J, Pilatus U, Hubers A, Wahl M, Ziemann U: Combined (1) $\mathrm{H}$ and (31)P spectroscopy provides new insights into the pathobiochemistry of brain damage in multiple sclerosis. NMR Biomed 2011, 24:536-546.

304. Inglese M, Liu S, Babb JS, Mannon LJ, Grossman RI, Gonen O: Three-dimensional proton spectroscopy of deep gray matter nuclei in relapsing-remitting MS. Neurology 2004, 63:170-172.

305. Gustafsson MC, Dahlqvist O, Jaworski J, Lundberg P, Landtblom AM: Low choline concentrations in normal-appearing white matter of patients with multiple sclerosis and normal MR imaging brain scans. AJNR Am J Neuroradiol 2007, 28:1306-1312.

306. Richards TL: Proton MR spectroscopy in multiple sclerosis: value in establishing diagnosis, monitoring progression, and evaluating therapy. Am J Roentgenol 1991, 157:1073-1078.

307. Davie CA, Hawkins CP, Barker GJ, Brennan A, Tofts PS, Miller DH, McDonald Wl: Serial proton magnetic resonance spectroscopy in acute multiple sclerosis lesions. Brain 1994, 117:49-58.

308. Simone IL, Federico F, Trojano M, Tortorella C, Liguori M, Giannini P, Picciola E, Natile G, Livrea P: High resolution proton MR spectroscopy of cerebrospinal fluid in MS patients. Comparison with biochemical changes in demyelinating plaques. J Neuro/ Sci 1996, 144:182-190. 
309. Brooks JC, Roberts N, Whitehouse G, Majeed T: Proton magnetic resonance spectroscopy and morphometry of the hippocampus in chronic fatigue syndrome. Br J Radiol 2000, 73:1206-1208.

310. Chaudhuri A, Condon B, Gow J, Brennan D, Hadley D: Proton magnetic resonance spectroscopy of basal ganglia in chronic fatigue syndrome. Brain Imaging 2003, 14:225-228.

311. Puri BK, Counsell SJ, Zaman R, Main J, Collins AG, Hajnal JV, Davey NJ: Relative increase in choline in the occipital cortex in chronic fatigue syndrome. Acta Psychiatr Scand 2002, 106:224-226.

312. Tomoda A, Miike T, Yamada E, Honda H, Moroi T, Ogawa M, Ohtani Y, Morishita S: Chronic fatigue syndrome in childhood. Brain Dev 2001, 22:60-64.

313. Sharma KR, Kent-Braun J, Mynhier MA, Weiner MW, Miller RG: Evidence of an abnormal intramuscular component of fatigue in multiple sclerosis. Muscle Nerve 1995, 18:1403-1411.

314. Steens A, de Vries A, Hemmen J, Heersema T, Heerings M, Maurits $N$, Zijdewind I: Fatigue perceived by multiple sclerosis patients is associated with muscle fatigue. Neurorehabil Neural Repair 2012, 26:48-57.

315. Flachenecker P, Bihler I, Weber F, Gottschalk M, Toyka KV, Rieckmann P. Cytokine mRNA expression in patients with multiple sclerosis and fatigue. Mult Scler 2004, 10:165-169.

316. Goebel MU, Baase J, Pithan V, Exton M, Saller B, Schedlowski M, Limmroth V: Acute interferon beta-1b administration alters hypothalamic-pituitary -adrenal axis activity, plasma cytokines and leukocyte distribution in healthy subjects. Psychoneuroendocrinol 2002, 27:881-892.

317. Hautecoeur P, Forzy G, Gallois P, Demirbilek V, Feugas O: Variations of IL2, IL6, TNF alpha plasmatic levels in relapsing remitting multiple sclerosis. Acta Neurol Belg 1997, 97:240-243.

318. Pokryszko-Dragan A, Frydecka I, Kosmaczewska A, Ciszak L, Bilinska M, Gruszka E, Podemski R, Frydecka D: Stimulated peripheral production of interferon-gamma is related to fatigue and depression in multiple sclerosis. Clin Neurol Neurosurg 2012, 114:1153-1158.

319. Heesen C, Nawrath L, Reich C, Bauer N, Schulz KH, Gold SM: Fatigue in multiple sclerosis: an example of cytokine mediated sickness behaviour? J Neurol Neurosurg Psychiatry 2006, 77:34-39.

320. Sharma KR, Kent-Braun J, Mynhier MA, Weiner MW, Miller RG: Evidence of an abnormal intramuscular coponet of fatigue in multiple sclerosis. Muscle Nerve 2009, 18:1403-1411.

321. Konecny L, Pospisil P, Dufek M, Drlikova L, Anbais FH, Erajhi AA, Dobsak P, Vank $P$, Siegelova J: Functional impairment in multiple sclerosis. Scripta Medica (BRNO) 2007, 80:225-232.

322. Lenman AJ, Tulley FM, Vrbova G, Dimitrijevic MR, Towle JA: Muscle fatigue in some neurological disorders. Muscle Nerve 1989, 12:938-942.

323. Kent-Braun JA, Sharma KR, Miller RG, Weiner MW: Postexercise phosphocreatine resynthesis is slowed in multiple sclerosis. Muscle Nerve 1994, 17:835-841.

324. Kent-Braun JA, Ng AV, Castro M, Weiner MW, Gelinas D, Dudley GA, Miller RG: Strength, skeletal muscle composition, and enzyme activity in multiple sclerosis. J Appl Physiol 1997, 83:1998-2004.

325. Petajan JH, White AT: Motor-evoked potentials in response to fatiguing grip exercise in multiple sclerosis. Clin Neurophysiol 2000 111:2188-2195

326. Leocani L, Rovaris M, Boneschi FM, Medaglini S, Rossi P, Martinelli V, Amadio S, Comi G: Multimodal evoked potentials to assess the evolution of multiple sclerosis: a longitudinal study. J Neurol Neurosurg Psychiatry 2006, 77:1030-1035

327. Di Lazzaro V, Oliviero A, Profice P, Ferrara L, Saturno E, Pilato F, Tonali P: The diagnostic value of motor evoked potentials. Clin Neurophysiol 1999, 110:1297-1307.

328. Colombo B, Martinelli Boneschi F, Rossi P, Rovaris M, Maderna L, Filippi M, Comi G: MRI And motor evoked potential findings in nondisabled multiple sclerosis with and without fatigue. J Neurol 2000, 247:506-509.

329. Zeller D, Aufm Kampe K, Biller A, Stefan K, Gentner R, Schutz A, Bartsch A, Bendszus M, Toyka KV, Rieckmann P, Classen J: Rapid-onset central motor plasticity in multiple sclerosis. Neurology 2010, 74:728-735.

330. Ng AV, Miller RG, Gelinas D, Kent-Braun JA: Functional relationships of central and peripheral muscle alterations in multiple sclerosis. Muscle Nerve 2004, 29:843-852.

331. Kuspinar A, Andersen RE, Teng SY, Asano M, Mayo NE: Predicting exercise capacity through submaximal fitness tests in persons with multiple sclerosis. Arch Phys Med Rehabil 2010, 91:1410-1417.
332. Savci S, Inal-Ince D, Arikan H, Guclu-Gunduz A, Cetisli-Korkmaz N, Armutlu K, Karabudak R: Six-minute walk distance as a measure of functional exercise capacity in multiple sclerosis. Disabil Rehabil 2005, 27:1365-1371.

333. Bakshi R, Miletich RS, Kinkel PR, Emmet ML, Kinkel WR: High-resolution fluorodeoxyglucose positron emission tomography shows both global and regional cerebral hypometabolism in multiple sclerosis. J Neuroimaging 1998, 8:228-234.

334. Bakshi R, Shaikh ZA, Miletich RS, Czarnecki D, Dmochowski J, Henschel K, Janardhan V, Dubey N, Kinkel PR: Fatigue in multiple sclerosis and its relationship to depression and neurologic disability. Mult Scler 2000, 6:181-185.

335. Blinkenberg M, Rune $K$, Jensen CV, Ravnborg M, Kyllingsbaek S, Holm S, Paulson OB, Sorensen PS: Cortical cerebral metabolism correlates with MRI lesion load and cognitive dysfunction in MS. Neurology 2000, 54:558-564.

336. Murai H, Kiyosawa M, Suzuki Y, Mizoguchi S, Ishii K, Ishikawa K, Akashi T: A case of multiple sclerosis with homonymous hemianopia examined by positron emission tomography. Jpn J Ophthalmol 2004, 48:591-593.

337. De Keyser J, Steen C, Mosert JP, Koch MW: Hypoperfusion of the cerebral white matter in multiple sclerosis: possible mechanisms and pathophysiological significance. J Cereb Blood Flow Metabol 2008, 28:1645-1651.

338. Zamboni P, Menegatti E, Weinstock-Guttman B, Dwyer MG, Schirda CV Malagoni AM, Hojnacki D, Kennedy C, Carl E, Bergsland N, Magnano C, Bartolomei I, Salvi F, Zivadinov R: Hypoperfusion of brain parenchyma is associated with the severity of chronic cerebrospinal venous insufficiency in patients with multiple sclerosis: a cross-sectional preliminary report. BMC Med 2011, 9:22.

339. Tang PPZ, White AT, Topaz S, Petajan JH: Abstract. Muscle energy metabolism in multiple sclerosis measured by in vivo 31P Mrs 476. Med Sci Sports Exerc 1997, 29:83.

340. Hu J, Xu Y, Jiang Q, Sehgal V, Shen Y, Xuan Y, Xia Y: Spectral pattern of total creatine and trimethyl ammonium in multiple sclerosis. Magn Reson Imaging 2004, 22:427-429.

341. Inglese M, Park SJ, Johnson G, Babb JS, Miles L, Jaggi H, Herbert J, Grossman Rl: Deep gray matter perfusion in multiple sclerosis: dynamic susceptibility contrast perfusion magnetic resonance imaging at $3 \mathrm{~T}$. Arch Neurol 2007, 64:196-202.

342. Sacco P, Hope PA, Thickbroom GW, Byrnes ML, Mastaglia FL: Corticomotor excitability and perception of effort during sustained exercise in chronic fatigue syndrome. Clin Neurophysiol 1999, 110:1883-1891.

343. Samii A, Wassermann E, Ikoma K, Mercuri B, George MS, O'Fallon A, Dale JK, Straus SE, Hallett M: Decreased postexercise facilitation of motor evoked potentials with chronic fatigue or depression. Neurology 1996, 47:1410-1414

344. Samii A, Wassermann EM, Ikoma K, Mercuri B, Hallett M: Characterization of postexercise facilitation and depression of motor evoked potentials to transcranial magnetic stimulation. Neurology 1996, 46:1376-1382.

345. Starr A, Scalise A, Gordon R, Michalewski H, Caramia M: Motor excitability in chronic fatigue syndrome. Clin Neurophysiol 2000, 111:2025-2031.

346. Chaudhuri A, Behan P: Fatigue and basal ganglia. J Neurol Sci 2000, 179:34-42.

347. Chaudhuri A, Behan P: Neurological dysfunction in chronic fatigue syndrome. JCFS 2000, 6:51-68.

348. Schillings ML, Kalkman JS, van der Werf SP, van Engelen BG, Bleijenberg G, Zwartz MJ: Diminished central activation during maximal voluntary contraction in chronic fatigue syndrome. Clin Neurophysiol 2004, 115:2518-2524.

349. Kent-Braun JA, Sharma KR, Weiner MW, Massie B, Miller RG: Central basis of muscle fatigue in chronic fatigue syndrome. Neurology 1993, 43:125-131.

350. Newham DJ, Davies JM, Mayston MJ: Voluntary force generation and activation in the knee muscles of stroke patients with mild spastic hemiparesis. J Physiol 1995, 483:128.

351. Kent-Braun JA, Miller RG: Central fatigue during isometric exercise in amyotrophic lateral sclerosis. Muscle Nerve 2000, 2000:909-914.

352. Davey NJ, Puri BK, Nowicky AV, Main J, Zaman R: Voluntary motor function in patients with chronic fatigue syndrome. J Psychosom Res 2001, 50:17-20.

353. Davey NJ, Puri BK, Catley M, Main J, Nowicky AV, Zaman R: Deficit in motor performance correlates with changed corticospinal excitability in patients with chronic fatigue syndrome. Int J Clin Pract 2003, 57:262-264. 
354. Araque A: Astrocyte-neuron signaling in the brain-implications for disease. Curr Opin Investig Drugs 2006, 7:619-624.

355. Chvatal A, Anderov M, Neprasova H, Prajerova I, Benesova J, Butenko O, Verkhratsky A: Pathological potential of astroglia. Physiol Res 2008, 57:S101-S110.

356. Yoshiuchi K, Farkas J, Natelson BH: Patients with chronic fatigue syndrome have reduced absolute cortical blood flow. Clin Physiol Funct Imaging 2006, 26:83-86.

357. Unger ER, Miller AH, Jones JF, Drake DF, Tian H, Pagnoni G: Decreased basal ganglia activation in chronic fatigue syndrome subjects is associated with increased fatigue. FASEB J 2012, 26:1035.20.

doi:10.1186/1741-7015-11-205

Cite this article as: Morris and Maes: Myalgic encephalomyelitis/chronic fatigue syndrome and encephalomyelitis disseminata/multiple sclerosis show remarkable levels of similarity in phenomenology and neuroimmune characteristics. BMC Medicine 2013 11:205.

\section{Submit your next manuscript to BioMed Central and take full advantage of:}

- Convenient online submission

- Thorough peer review

- No space constraints or color figure charges

- Immediate publication on acceptance

- Inclusion in PubMed, CAS, Scopus and Google Scholar

- Research which is freely available for redistribution 